\title{
POSMODERNIDAD Y NARRATIVA. LA DISCUSIÓN SOBRE EL FUNDAMENTO DEL SELF1
}

\author{
PABLO LÓPEZ-SILVA \\ Universidad de Tarapacá, Chile \\ The University of Manchester, United Kingdom
}

\begin{abstract}
RESUMEN: Este artículo presenta y discute dos de las principales concepciones acerca del origen y naturaleza de la narrativa del «self» en la posmodernidad, i.e., la conciencia que cada uno tiene - desde el punto de vista en primera persona- acerca de sí mismo como la misma persona en diferentes instantes de tiempo. Estas posiciones son las siguientes: a) la teoría de Kenneth Gergen en la cual el "self» es una construcción conversacional que emerge de discursos sociales previos al sujeto, y b) la teoría de Vittorio Guidano en la que el self es un fenómeno experimentado que luego deviene simbolizado, entre otras posibilidades, narrativamente. Se propone que los argumentos por los cuales Gergen defiende su teoría son inconsistentes, especialmente cuando se refiere al origen de la realidad y al de la narrativa del «yo». PALABRAS CLAVE: Sí-mismo, narrativa del sí mismo, Kenneth Gergen, Vittorio Guidano, Continuidad.
\end{abstract}

\section{Postmodernism and Narrative. The discussion regarding the foundation of the self}

ABSTRACT: This paper presents and discusses two of the mains conceptions about the origin and the nature of the narrative of the "self» in the postmodernity, i. e., the consciousness that each one has - from the first person perspective- about oneself as the same person in different instants of time. Those positions are: (a) the theory of Kenneth Gergen in which the "self» is a conversational construction that emerges from social discourses previous to the subject; and $(b)$ the theory of Vittorio Guidano in which the «self» is, firstly, an experienced phenomenon that becomes symbolized in a second moment, among other possibilities, narratively. It will be proposed that the arguments by which Gergen defends his theory are inconsistent, especially when it comes to the origin of the narrative of the self and their meaning.

KEY WORDS: Self, narrative of the self, Kenneth Gergen, Vittorio Guidano, Continuity.

\section{INTRODUCCIÓN}

Las diversas reconfiguraciones que el concepto "yo» o «self» ha sorteado en la posmodernidad ha llevado a diversos filósofos y psicólogos a indicar que éste se ha disuelto en medio de narraciones e interaccionales-sociales ${ }^{2}$, juegos lingüísticos ${ }^{3}$, condiciones político-históricas, entre otras opiniones ${ }^{4}$. Por el contrario, algunos autores proponen la existencia de un self pre-reflexivo continuo como uno de los procesos medulares que estructuran la experiencia humana ${ }^{5}$. En este escenario, por tanto, la cuestión principal se torna hacia el debate acerca de la fragmentación o la continuidad del self ${ }^{6}$, y cómo el énfasis en la dispersión-fragmentación produce diversas consecuencias en el plano filosófico.

\footnotetext{
Quisiera agradecer al Dr. Mauricio Otaiza y al Dr. José Tomas Alvarado por sus valiosos comentarios en versiones previas de este artículo. Mi escritura de la versión final de este trabajo fue auspiciada por el programa BECAS-CHILE de la Comisión Nacional de Ciencia y Tecnología (CONICYT) del Gobierno de Chile.

MeAd (1934); Gergen (1985).

3 Shotter (1993); Potter y Wetherell (1987).

4 Destacan la deconstrucción derridiana (1967); las críticas a las concepciones modernas del Yo de SAMPSON (1983) y HolLinger (1994); entre otros.

5 Cfr. Merleau-Ponty (1984), Henry (1991), Gendlin (2007), Ratcliffe (2008). Cfr. las revisiones propuestas por psicoterapeutas y psiquiatras como Guidano $(1987,1994)$, Arciero (2005), Arciero y BoNDOLFI (2009), LAmbruschi (2009) y NARdi, B., (2006), NARdi y Bellantuono (2008), entre otros.

6 Arciero (2005).
} 
En este plano, entenderemos al self como el proceso por el cual el «yo» se sabe «sí mismo» y tiene noticia de su identidad en diferentes momentos y contextos. Así, una de las modalidades más importantes de este proceso la constituye la dimensión narrativa del self. De este último punto se desprenden la problemáticas que analizaremos a la luz de dos posiciones antagónicas respecto del origen de las narraciones que sustentan al self.

El presente trabajo contrasta las ideas de Kenneth Gergen —quien apuesta por la fragmentación del sentido del sí mismo- con las de Vittorio Guidano, quien defiende la continuidad del self como proceso ${ }^{7}$. Se elabora un análisis crítico de los argumentos entregados por Gergen respecto del concepto de self, tomando como referencia la posición de Guidano, y los aportes de diversas áreas del conocimiento, tales como la fenomenología, la filosofía del lenguaje, la psicología del desarrollo, entre otros. Finalmente, se ofrecen conclusiones sobre la aplicabilidad, consistencia y coherencia de los conceptos ofrecidos por los autores para definir la forma en que el yo tiene noticia de su identidad a través del tiempo.

\section{El SELF EN LA POSMODERNIDAD. ENTRE FRAGMENTACIÓN Y CONTINUIDAD}

El debate entre Guidano y Gergen se da en un contexto posmoderno, donde hablar de «posmodernidad» es particularmente complejo ${ }^{8}$. Para Lyotard ${ }^{9}$ la posmodernidad no constituye un corpus teórico uniforme, sino que conlleva una actitud que: «refina nuestra sensibilidad a las diferencias e incrementa nuestra tolerancia a la inconmensurabilidad $»^{10}$. El concepto de "paradigma $»^{11}$ nos sirve como criterio para señalar la existencia de diferentes sensibilidades al interior de una misma época. Sin embargo, a pesar de estas diversas sensibilidades, en la posmodernidad parece haber un hilo conductor claro en, al menos, tres asuntos:

\subsection{Los antecedentes ${ }^{12}$}

Un antecedente directo del posmodernismo es el énfasis en la circunstancialidad del sujeto puesto de relieve por Nietzsche ${ }^{13}$, el cual hace prescindir al self de cualquier fundamento metafísico y sitúa la corporalidad —en tanto entidad que toma posesión de la

${ }^{7}$ Esta distinción se observa también en el título de las obras más emblemáticas de ambos autores respecto del concepto de self. GERGEN (1992) tituló su obra: The satured self; mientras que GuIDANO (1994) denominó a su obra The self in process.

8 Terry Eagleton (1998) distingue entre "posmodernidad», que refiere a un período histórico en donde se critican las nociones de verdad, objetividad y razón, y el término "posmodernismo», una expresión de la cultura contemporánea. No obstante, hoy no parecen emplearse con mayores diferencias.

9 LyotaRd (1989) indica: «El término realidad no implica en absoluto una remisión a una sustancia material» (p. 76).

10 Lyotard en Owens (1986), p. 93.

${ }_{11}$ KuHN (1978) indica lo siguiente: «Paradigma es aquello que los miembros de una comunidad científica, y solo ellos, comparten, y a la inversa, es la posesión de un paradigma común lo que constituye a un grupo de personas en una comunidad científica, grupo que de otra manera estaría formando por miembros inconexos» (pp. 12-13).

12 Para profundizar el análisis: Cfr. Lyotard (1989) y Eagleton (1998). Vattimo, G., (2004) ofrece un exhaustiva revisión de los antecedentes del posmodernismo junto a sus principales ideas. Hoyos (2005) ofrece un breve estudio introductorio para la comprensión de la psicología en la posmodernidad.

${ }_{13}$ Sobre Nietzsche, VAтTIMO (1990b) indica que éste ha mostrado que la existencia de una realidad racionalmente adecuada sobre un fundamento metafísico es sólo un «mito tranquilizador». Ya no existiría una 
circunstancialidad- como uno de sus fundamentos más importantes. Así, Nietzsche indica: «Detrás de tus pensamientos y sentimientos, hermano mío, se encuentra un soberano poderoso, un sabio desconocido - llámase sí mismo [Selbst]—. En tu cuerpo habita, es tu cuerpo» ${ }^{14}$.

Por otro lado, autores como Vattimo ${ }^{15}$, reconocen en Heidegger otro de los antecedentes fundamentales del posmodernismo. Básicamente, la esencial apertura del lenguaje a nuevos significados hace que no exista la primacía especial de unos sobre otros. Por lo tanto, no podrá existir de modo justificado, ninguna pretensión de verdad ${ }^{16}$. Sin embargo, autores como Grondin advierten que tal relación es forzada y la discuten desde el mismo trabajo de Heidegger ${ }^{17}$.

\subsection{El análisis de un «self» sin fundamento metafísico}

Teicholz indica que el self en la posmodernidad, entendido como estructura psicológica perdurable y coherente - en el sentido cartesiano-, es una idea cuestionada ${ }^{18}$. Guidano criticará también la visión tradicional cartesiana de self como «núcleo invariable» ${ }^{19}$. Dado que en la posmodernidad la identidad personal es variable y dinámica, el self ya no es unitario, sino que múltiple ${ }^{20}$. El self fluctúa y no es un centro de iniciativa aislado, sino que está constituido intersubjetivamente en y con una historicidad ${ }^{21}$. En consecuencia, la posmodernidad propone un cambio epistemológico fundamental, a saber, el radical abandono de la noción sustancialista del racionalismo imperante en la filosofía cartesiana y la psicología tradicional. El self pasa de ser una «entidad» a un «proceso» ${ }^{22}$.

«verdad universal», sino que «verdades contextualizadas», por esto, tampoco la historia tendría un sentido definido. Según Hoyos (2005), el pensamiento de Nietzsche nos introduce al «nihilismo» al no existir un punto de referencia común y un fundamento axiológico que sustente la realidad.

14 Nietzsche (1994), pp. 60-61.

15 Vattimo (1990a).

16 Vatтimo (1990c) indica que: «Este consumo como sistema de intercambio o lenguaje se basa en la ambigüedad de los signos, que sublima el estatuto de utilidad real de los objetos; de tal manera que no se consume el objeto en sí mismo, según su valor utilitario, sino como signo que nos distingue» (p. 85).

17 Grondin (1996) refiere a ciertos elementos propios de la posmodernidad del siguiente modo: «es la idea de que los fenómenos con los que la filosofía tendría que habérselas, serían datos impregnados ya de interpretación. Hacer hermenéutica sería entonces recordar que los fenómenos mismos dependen ya del orden interpretativo. En otras palabras, Heidegger sostendría que no hay jamás algo así como "las cosas mismas", lo que ya de por sí justificaría la entrada en escena de la hermenéutica. Contra esta interpretación, vaga y general, de la intervención hermenéutica de la fenomenología, pienso que se pueden hacer valer dos argumentos. Primeramente, el propio Heidegger no ha dicho jamás —ni en el texto de SZ, ni en los pasajes pertinentes de sus cursos- que tal es el modo como habría de enfocar la relación de la fenomenología con la hermenéutica. Uno piensa, más bien, en Nietzsche o en Richard Rorty cuando oye decir que no hay fenómenos, sino tan sólo interpretaciones. En segundo lugar, es importante recordar que Heidegger no opone jamás la hermenéutica a la idea de una legitimación por las cosas mismas. Se le podrá acusar de ingenuo, pero si Heidegger hace hermenéutica no es porque no haya las cosas mismas, sino, por el contrario, para abrirse acceso a ellas» (p. 81).

18 Teicholz (1999).

19 Guidano (1998a) indica que: "Ya casi nadie lo considera [al self] como entidad en el sentido tradicional racionalista cartesiano - del cogito ergo sum - como un self sin contexto, un self impersonal. Este ya no es el self concebido tradicionalmente, como una especie de constructo, de entidad central. Es cierto, hoy esta visión ya no rige más» (p. 1).

${ }_{20}$ Cfr. Deleuze (1989).

21 Stolorow y Atwood (1992); Mitchell (1993).

22 Esta propuesta se puede entender, al menos, de dos maneras: a) como proceso vincular y ortogenético: Guidano (1998a); NeIMEYer y Mahoney (1998); NARdi (2006); b) Como proceso social: Gergen (1992); Crespo (2001); Revilla (2003), entre otros. 


\subsection{El énfasis en el lenguaje como medio de comprensión del «self»}

La posmodernidad propone el giro hacia el lenguaje como principal medio de comprensión del self ${ }^{23}$ y la realidad ${ }^{24}$. Por ejemplo, para el postestructuralismo, el lenguaje humano es en sí el estructurante de las cosas y de la realidad, por tanto, la comprensión del self debe situarse en el discurso y olvidar cualquier argumentación metafísica. A su vez, la estructura lingüística originaria de las cosas: «no refleja una realidad social preexistente, sino que la constituye $»^{25}$. El self es una configuración lingüística, y al tomar los símbolos lingüísticos compartidos socialmente, reproduce comprensiones sociales previas de la realidad ${ }^{26}$. Según Gergen el self se fragmenta en cada contexto en la medida que cada contexto posee diferentes discursos que informan al self de lo que es de forma divergente y antagónica ${ }^{27}$.

Dentro de este contexto posmoderno, existirá una vertiente filosófica que intenta comprender de forma diferente el proceso mediante el cual el yo tiene noticia de sí mismo en su acontecer. Algunos psicólogos y fenomenólogos (Guidano, 1984; Henry, 1991; Gendlin, 1993 y 2007; Arciero y Bondolfi, 2011) indican que el lenguaje, si bien es la modalidad más importantes de simbolizar el acontecer del yo, no es la única. Para estos autores, la existencia humana es un devenir tácito o pre-lingüístico. Así, en esta praxis vital podrán existir simbolizaciones del acontecer del yo no mediadas por palabras, tales como: las expresiones artísticas, los síntomas psicopatológicos, los rituales obsesivos, entre otros. Por otro lado, las simbolizaciones lingüísticas aportan una mayor definición a la experiencia del sujeto en el mundo, concatenándose con ésta (Gendlin, 1993). Lo común para todas las formas de simbolización del devenir existencial es que todas tienen como fundamento la experiencia misma del sujeto. De esta manera, nuestras comprensiones sobre la realidad y el sí mismo, se originan en las experiencias que tenemos de éstas. La noticia que cada uno tiene sobre su yo, surge de la experiencia de ser uno mismo, y ésta experiencia es, primordialmente, tácita.

Dentro de este marco conceptual que pone énfasis, en mayor o menor medida, en el lenguaje como medio de acceso al self, una de las propuestas más influyentes la constituye el denominado «movimiento narrativo». Esta tradición se centra en la narración que el sujeto realiza de su existencia en el mundo, siendo las narraciones el sustento del self.

Es en este escenario donde la problemática entre ambas posturas a tratar comienza a gestarse, precisamente, al describir el origen de las narraciones que sustentan al self.

${ }_{23}$ Una clara influencia a tal propuesta está en Wittgenstein, L., quien plantea la existencia de un isomorfismo entre lenguaje y mundo posible. Al no poder conocerse la esencia de las cosas, solo el lenguaje les daría forma y las limitaría. El mundo solo toma forma en los límites del lenguaje (Cfr. WiTTGENSTEIN [1988]).

24 Cfr. Maturana (1988); Sarup (1993); Shotter (1993); Echeverría (1994). Para una introducción al giro lingüístico y la posmodernidad, revisar GARcía-LoRENTE (2008).

25 Revilla (2003, p. 10).

26 Refiriéndose a esto, Arciero (2005) indica lo siguiente: «[En la posmodernidad] la operación de disolución del sujeto se sustenta por la separación entre el significado y la experiencia [el significado] se define por la diferencia con otros significados, dentro de un sistema lingüístico cerrado: O sea, que no tiene ninguna relación con el mundo extralingüístico. [...] La primacía del lenguaje sobre la experiencia lleva a una concepción del individuo que adquiere un sí mismo cambiante que se adhiere continuamente a las múltiples formas de discurso que componen el universo lingüístico a él pre-existente» (p. 27).

${ }^{27}$ Gergen (1985). Sobre esta idea, Cfr. Cabrera (2006). Según Derrida (1984), la identidad quedará situada en las posibilidades lingüísticas en las que participa, y aunque no es continua, señala que: "yo nunca he dicho que el sujeto debe ser omitido [que es lo que observaremos el autores como GERGEN (1992)]. Sólo que debe ser deconstruido. Decontruir el sujeto no significa negar su existencia. Hay sujetos, operaciones o efectos de la subjetividad. Este es un hecho incontrovertible [...] Mi trabajo no es entonces destruir al subjeto; es simplemente tratar de resituarlo» (p. 125). 
Para algunos, las narraciones que sustentan al self pueden originarse en la praxis táci$\mathrm{ta}^{28}$, experiencia «antepredicativa $»^{29} \mathrm{O}$ «experiencia pre-narrativa $»^{30}$. En contraste, para otros, las narrativas del self tienen su origen en ordenamientos y discursos previos al "yo", por lo cual el self, solo reproduciría discursos sociales en los cuales está inmerso ${ }^{31}$. Es en este escenario epistemológico general, donde las ideas de Guidano y Gergen se enfrentan. Pues bien, discutamos ahora las respectivas posiciones.

\section{La discusión entre las ideas de Guidano y las ideas de Gergen}

Si bien, Guidano criticó abiertamente la visión del self de Gergen, esto no generó un debate especial entre los autores. Este trabajo presenta, más bien, un estudio de las ideas y argumentos de cada autor y una profundización del debate entre ambas posiciones.

Parece prudente en este punto preguntar: ¿están ambos autores hablando de lo mismo? Pues bien, creemos que ambos autores, aunque adscriben diferentes características y origines a los términos, hablan del mismo asunto, debido a los siguientes motivos: a) Ambos autores emplean el término "self»: Guidano parece reconocerlo así en su crítica a Gergen $^{32}$.b) Ambos autores se refieren al Yo, en tanto poseedor de «conciencia de sí mismo»: Guidano sugiere este asunto en el texto recién citado en la nota 32 el cual puede ser confrontado con el empleo del término en Gergen quien señala: "Cuando se enterró al Yo como realidad consistente y pasó a ser construido y reconstruido en múltiples contextos, se derivó a la fase del yo relacional, en que el sentido de la autonomía individual dio paso a una realidad de inmersión en la interdependencia, donde las relaciones del yo son las que lo construyen ${ }^{33}$.c) Ambos autores comprenden de modo narrativo la dimensión explícita del self: Para Gergen, tenemos acceso al self y a su comprensión desde una narrativa que se origina en discursos sociales anteriores al sujeto ${ }^{34}$. Para Guidano, en cambio, el self es un fenómeno fundamentalmente tácito. Para el autor, la narrativa tiene su base en la experiencia inmediata del sujeto. Sin embargo, al igual que Gergen, Guidano sostiene que el self puede narrar su existir de un modo explícito a través del lenguaje.

\subsection{La propuesta socioconstruccionista de Kenneth Gergen}

3.1.1. Premisas epistemológicas: Gergen ${ }^{35}$ toma distancia de la influencia de Berger y Luckmann ${ }^{36}$, indicando que el discurso y las narraciones generan exclusivamente la

28 GendLin (1993).

29 Merleau-Ponty (1984).

30 Ricoeur (1986, 1993); Guidano (1993); Arciero y Guidano (2000).

31 Potter y Wetherell (1996); Gergen (2000).

32 «El self es esencialmente un proceso, no es una entidad, no es una estructura, ni un conjunto de estructuras, si no que es el proceso que da a toda esta estructura una configuración de totalidad [...] También me refiero a otro aspecto, en el cual de nuevo se concibe un self de tipo acontextual, sin tomar en cuenta el contexto. Me refiero al concepto de self vacío, «the empty self» de Gergen. Gergen tiene un libro muy famoso «El self saturado», que es prácticamente el self actual y disuelto. Es una entidad ilusoria y emblemática de la situación post-moderna. Yo creo, que esto es un modo de acercarse al problema de la transformación de la conciencia contemporánea, sacándola del contexto evolutivo y de desarrollo» (GuIDANO, 1998a, p. 1).

33 Gergen (1994, p. 192).

34 Cf. Gergen (2001); Jubés et al. (2000).

35 Sus principales influencias provienen de la obra de BERGER y LUCKMANN (1983); la teoría de las representaciones sociales de Moscovici (1961); el análisis de discurso (Potter y Wetherell, 1987; PotTer, 1996); el planteamiento dialógico de Hermans (1993), y la psicología social crítica de SAMPSON (1983), entre otros.

36 BERgER y LuCKMANN (1983). 
realidad y la conciencia del sí mismo ${ }^{37}$, ideas que tales autores negarían reconociendo que si bien los procesos de mantención de las pautas culturales se re-editan en el lenguaje, existirían otros procesos implicados también. Para Gergen, la narrativa personal no hace referencia a la experiencia del sujeto sino que reproduce el discurso social desde el cual emerge. En efecto, según Gergen, es por medio de los discursos sociales pre-existentes al sujeto por medio de los cuales el yo tiene noticia de su identidad a través del tiempo $^{38}$. Por otro lado, la realidad será una construcción social que se elaborará dentro de un marco sociocultural determinado. La realidad es, a fin de cuentas, un conjunto de significados conversacionales que son socialmente compartidos ${ }^{39}$.

3.1.2. El «self» en Gergen: Para Gergen, el self es una construcción conversacional explícita que toma su sentido en la ejecución de un rol. El funcionamiento y la conciencia del sujeto estarán determinadas por las pautas culturales de acción que rigen cada contexto $^{40}$. Así, el soporte del self son los discursos sociales negociados en el lenguaje, identificando el sujeto un sentido compartido de sí mismo mediante las formas conversacionales contextuales ${ }^{41}$.

Para Gergen, el self toma su forma en tanto identificación discursiva dentro de un universo lingúistico pre-existente ${ }^{42}$. Como premisa epistemológica básica, para el autor, solamente podemos obtener información sobre nosotros mismos por medio del lenguaje, por consiguiente, el empleo de las palabras ya viene contaminado por ideologías, representaciones sociales, discursos sociales, etc. En efecto, los discursos sociales reproducidos en las conversaciones cotidianas ofrecen el anclaje suficientemente necesario para tener noticia de mí mismo.

Gergen se apoya en algunas tesis de Wittgenstein para sugerir que los límites del lenguaje constituyen los límites del mundo y del self $f^{43}$. Esto se torna particularmente relevante para el autor en lo que respecta al «lenguaje del yo», dado que serán los términos y palabras que disponemos para definirnos los que impondrán los límites de nuestra experiencia, de nuestra realidad y, en definitiva, de nuestra conciencia de nosotros mismos. Gergen llega radicalmente a sugerir que: «sin las formas del lenguaje no se podría afirmar que se tenga experiencia alguna» ${ }^{44}$.

La tesis de "la saturación social del self»" claramente es la que mejor caracteriza la comprensión del concepto en Gergen. Para éste, la conciencia de ser sí mismo se genera por las narrativas explícitas sobre el Yo. La diversidad de contextos y relaciones que la posmodernidad ha permitido genera un superávit de información al tratar de definir

${ }_{37}$ Cfr. Bravo (2002). Sobre esto, GERgEN (1992) señala lo siguiente: «La verdad parece ser una cuestión de perspectivas, y éstas productos de intercambios y consensos sociales, es decir, construidas en los sistemas de comunicación social» (p. 20).

${ }_{38}$ Lyddon (1995) señala que la esencia del pensamiento construccionista social es la noción de que las construcciones personales del entendimiento están determinadas por el medio social (1995).

39 Collier, Minton y Reynolds (2000).

40 Gergen (1992).

41 Cfr. Gergen (1885, 1992); Bravo (2002).

42 Sobre esto, BRAvo (2002) indica lo siguiente: «[Para Gergen] El yo será entendido para los construccionistas como una narración que se hace inteligible en el seno de las relaciones vigentes, a saber, un relato de relatos en tanto el sustrato del yo esté situado a partir de relatos de familiares, en los relatos de cuentos de hadas en la infancia, los relatos populares, el relato cotidiano de los sucesos de una mañana cualquiera, los relatos con un amigo, etc.» (p. 3).

43 Wittgenstein (1953).

${ }_{44}$ Gergen (1992, p. 149).

45 Gergen (1992). 
al yo. Poco a poco éste es colonizado por significados externos a éste. Cuando el Yo no soporta el superávit informacional comienza a saturarse, lo que en definitiva fragmenta la conciencia de ser un sí mismo (el self pasa a ser un «empty self»). Para Gergen, la multiplicidad relacional termina escindiendo y aniquilando toda noticia que el yo tiene de su identidad. Para el autor, el sujeto es multifrénico, lo que significa: «la escisión del individuo en una multiplicidad de investiduras [conversacionales] de su self ${ }^{46}$.

Para Gergen, el sí mismo se constituye y se comprueba desde las afirmaciones de otros. Esto es, precisamente, lo que posibilita su saturación. Para el autor, el Yo es una negociación intersubjetiva inestable y contexto-dependiente dado que se encuentra en un estado denominado «interdependencia precaria " $^{47}$. En efecto, el self surge en medio de redes de identidades en relación recíproca ${ }^{48}$. En este punto, para el autor, la estabilidad del sí mismo se verá determinada por dos factores: a) Los flujos de información presentes en las conversaciones y que definen la identidad, y $b$ ) La continuidad del acuerdo conversacional del contexto en el que se participa (calidad de la interdependencia precaria). Dado que para Gergen, el sentido del sí mismo proviene de las narrativas, el self, al estar expuesto a la diversidad contexual, es, constitutivamente, un self fragmentado ${ }^{49}$.

\subsection{La propuesta posracionalista de Vittorio Guidano}

3.2.1. Premisas epistemológicas: Guidano ${ }^{50}$ basa parte de su epistemología en el pensamiento de Maturana ${ }^{51}$, especialmente cuando éste indica que: «todo lo que hacemos, lo hacemos desde una emoción $»^{52}$. En efecto, para Guidano el sustrato del conocimiento lo constituye la experiencia emocional ${ }^{53}$. El modelo posracionalista ${ }^{54}$ de Gui-

46 Gergen (1994, p. 106). Sobre esto, Bravo (2002) comenta lo siguiente: «[El socioconstruccionismo:] descorre al yo como una unidad. Existiría una multiplicidad de selves en tanto distintas relaciones, esto es, las personas pueden autonarrarse de muchas maneras dependiendo del contexto relacional» (p. 5).

${ }_{47}$ Gergen (1996) indica que: «Este depender de los demás sitúa al actor en una posición de interdependencia precaria. Ya que del mismo modo que la autointeligibilidad depende de si los demás están de acuerdo sobre su propio lugar en el relato, también la propia identidad de los demás depende de la afirmación que de ellos haga el actor. El que un actor logre sostener una autonarración dada depende fundamentalmente de la voluntad de los demás de seguir interpretando determinados pasados en relación con él (p. 183).

48 GERgEN (1996) indica lo siguiente: «Dado que la identidad de uno puede mantenerse solo durante el espacio de tiempo que los otros interpretan su papel de apoyo, y dado que uno, a su vez, es requerido para interpretar papeles de apoyo en las construcciones de los otros, el momento en el que cualquier participante escoge faltar a su palabra, de hecho amenaza a todo el abanico de construcciones interdependientes. [...] Las identidades, en este sentido, nunca son individuales; cada una está suspendida en una gama de relaciones precariamente situadas» (p. 258).

49 Así, para Gergen en el self habitan múltiples posibilidades incluso muchas veces antagónicas de identificación contextual. El yo se sumerge y nada en las corrientes siempre cambiantes, concatenadas y disputables de un ser radicalmente relacional (SEOANE, 2005).

50 Posee múltiples influencias teóricas. Por un lado se apoya en la tradición cognitiva italiana (GUIDANO y LiotTi, 1979); la teoría del vínculo de Bowlby (1988); la Biología del Conocimiento y los sistemas autorreferenciales de Maturana y Varela (1984); la epistemología evolutiva de Campbell (1974); la teoría motora de la mente de Weimer (1977), y la teoría de los sistemas complejos (Prigonine, 1996, entre otros). Por otro lado, Guidano es influido por filósofos como Heidegger, M., Merleau-Ponty, M., Ricouer, P., entre otros pertenecientes a la tradición fenomenológica-hermenéutica.

51 Maturana $(1984 ; 1988)$.

52 Maturana (1989, p. 99).

53 Guidano (2001).

${ }_{54}$ Suele considerarse al posracionalismo como un tipo de «constructivismo». Sin embargo, existen algunas diferencias. 1) Mientras que en el posracionalismo las emociones son el elemento imprescindible en el proceso de construcción de la realidad como: a) formas de conocimiento; $b$ ) elementos del proceso 
dano ${ }^{55}$ sostiene que toda narrativa se fundamenta, en primer término, en la experiencia personal tácita del sujeto. Existe, por tanto, una experiencia básica que no se confunde con los símbolos o palabras que la representan o la narran.

Para Guidano, el conocimiento humano consiste en ser, básicamente, un proceso tácito y proactivo de atribución de significados a la experiencia inmediata ${ }^{56}$. Por esta razón el autor designa al self como una organización de significado personal (O.S.P.). Expliquemos el significado del término. Lo personal son, en primer lugar, las emociones experimentadas. El significado tiene, por su parte, dos momentos: a) un momento tácito que pertenece, precisamente, a la calidad de la emoción ya mencionada, y b) un momento simbólico-narrativo, que cualifica explícitamente lo sentido.

Para Guidano la existencia humana es, entre otras cosas, un constante devenir emocional, por lo que la necesidad narrativa surge como consecuencia del vivir en aquella praxis. Así, por medio de la narrativa, logramos cierta distancia de las experiencias inmediatas y podemos emplear símbolos autorreferenciales que las representan. En otras palabras, explicamos lo que nos acontece.

A diferencia de la propuesta de Gergen, las narraciones pueden tener el poder de unificar diferentes experiencias. Esto es lo que se conoce como «reconstrucción». Sin embargo no es la narración por sí sola sino la narración que da cuenta de la unidad tácita sentida- del yo la que es capaz de cumplir esta función.

3.2.2. El «self» en Guidano: Para Guidano toda comprensión humana deviene simbólica, y uno de sus aspectos antropológicos más esenciales es el momento explicativonarrativo ${ }^{57}$. La narración siempre es permitida por la sensación que la produce y que le da sustento. Por esto, la conciencia que tiene el Yo de ser sí mismo, en primer lugar un fenómeno tácito experimentado, que luego, mediante la simbolización narrativa, deviene explícito. El self para Guidano consiste en ser, entonces, un self system formado por, entre otros sistemas, el sistema emocional, el cognitivo, el motor, el verbal, etc.

La función del self system es la de percibirse a sí mismo y al entorno como un mundo familiar y estable ${ }^{58}$. A la base del funcionamiento de éste hay dos sensibilidades tácitas:

de conciencia, y c) factores fundamentales del proceso de cambio humano (BALBI, 2004), en el constructivismo, por otro lado, se le entrega la preeminencia en la construcción de la realidad dependerá de la semántica del lenguaje. Y mientras que en el constructivismo el énfasis de la investigación está en dilucidar cómo las personas construyen los significados que otorgan a la realidad, en el posracionalismo se intenta explicar cómo las personas sienten su identidad. 2) Mientras que el constructivismo el énfasis de la investigación está en dilucidar el modo cómo las personas narran y construyen los significados que otorgan a la realidad, en el posracionalismo se intenta dilucidar, en primer lugar, cómo las personas sienten su identidad. 3) Mientras que en el constructivismo no hay un significado primario de los términos, en el posracionalismo este significado se valida a partir de las emociones con las cuales el cliente reconoce ciertos significados y rechaza otros. 4) Mientras que en el constructivismo siempre es posible elaborar otros significados para los términos en uso, en el posracionalismo, en cambio, los significados tienen un soporte tácito y emocional que constituye un limite real a las posibilidades narrativas de las palabras porque, por lo demás, tales emociones no son arbitrarias. Sin embargo, hay que admitir que el propio Guidano no pocas veces pareció inscribir su modelo dentro de las vertientes constructivistas (Cfr. Guidano, 1995a; 1995b). El análisis de este asunto nos alejaría del objetivo del presente trabajo.

55 Guidano (1987; 1994; 1997, entre otros).

56 Mahoney (1991).

${ }_{57}$ Para Guidano - a diferencia de la propuesta de Gergen — existen dos tipos de simbolización de la experiencia: a) la forma pre-verbal (tácita) que se expresa por medio de —entre otros recursos-: la sintomatología, los rituales, rumiaciones, juegos, las expresiones artísticas tales como la música, la danza, la plástica, etc., y $b$ ) la forma verbal, que se expresa en palabras y que permite la narración explícita del sí mismo.

${ }_{58}$ GuIdano (1998b) señala lo siguiente: «La construcción de un sentido del sí mismo, es decir, de una manera de sentirse para con el entorno empieza ya, en los primeros meses de vida y corresponde a reu- 
La sensibilidad hacia a lo habitual (sameness o mismidad) y la sensibilidad hacia lo diverso (selfhood o ipseidad). Es decir, por un lado, la persona es sensible a las experiencias familiares (sameness) y, por otro lado, es sensible a las experiencias de carácter excepcional (selfhood). Ambas modalidades constituyen los procesos tácitos del Yo que fundamentan la particular forma de sentirse y experimentar a sí mismo, y configura, a su vez, sus posibilidades narrativas.

El sameness es la "permanencia de Mí mismo» en la multiplicidad del acontecer de mi praxis ${ }^{59}$. A lo largo de la vida, esta modalidad privada y anónima se complejiza ortogenéticamente ${ }^{60}$. Para Guidano, la existencia humana en esta sensibilidad es esa forma de percibirse a uno mismo y a la realidad, sin necesidad de tener que pensar. Finalmente, la mismidad se constituye como el dominio emotivo originario de las narraciones de las vivencias sociales ${ }^{61}$. Dicho de otro modo, en esta sensibilidad el yo ejecuta su praxis ${ }^{62}$.

Por otra parte, el selfhood es la "constancia de mí mismo», la sensibilidad que suma la multiplicidad del «quien» momento a momento. En esta sensibilidad el yo permite integrar los momentos en una trama narrativa coherente según las regularidades fundamentales del sameness. Aunque la narración sólo es una especie del género de la simbolización tampoco es cualquier especie. La narración es la que, para Guidano, cumple la función más potente en la reordenación de las coherencias del sameness, razón por la cual el autor se refiere al selfhood precisamente como self que «narra» la experiencia ${ }^{63}$.

nir, a armar esquemas emotivos de patrones recurrentes de experiencia inmediata. Esto es lo que hace que, en los primeros meses de vida, uno se perciba a sí mismo y al entorno como un mundo estable y familiar. El input sensorial, y esto lo sabemos gracias a los estudios neurofisiológicos y neurobiológicos, de por sí es siempre nuevo, pero la mente nunca se comporta como si fuera nuevo. Nos comportamos como si todo lo que nos rodea fuera normal, estable, conocido, familiar, pero cada percepción es única y nueva. Entonces se desarrolla desde un principio, diríamos, por una parte esta cara de la medalla, la continuidad, como la sensibilidad a lo que es canónico, es decir, a lo que nos es familiar, y por otro lado también una atención hacia lo que no es ordinario, hacia lo excepcional» (p. 4).

59 Naranjo (2008).

${ }_{60}$ Ya desde los veinte meses de vida un niño tiene sentido de lo canónico, lo que le permite adherirse a la estabilidad y familiaridad de lo que conoce, rechazando así, lo que no le es familiar (Cfr. BRUNER, 1984; 1986).

61 Para Guidano, los procesos autorrefenciales de ordenamiento de la experiencia se articulan evolutivamente y se ven determinados por el patrón vincular temprano (pattern) que el sujeto desarrolla con sus cuidadores en la niñez (apego) (Bowlby, 1973; 1988). Las regularidades afectivas derivadas de tal relación, fundamentan: la mismidad; el sentido de coherencia y continuidad; y los procesos tácitos afectivos del Yo, los cuales permiten las posteriores narraciones de la identidad experimentada.

${ }^{62}$ Guidano (1998b) señala: El sentido de continuidad del sameness es esencialmente emotivo, entonces es algo que se siente, no es necesario pensar en ello, esto no significa que luego no lo vamos a pensar, significa que del sentido de continuidad que advertimos de manera continuada, posteriormente vamos desarrollando teorías y explicaciones, las buscamos en las variables de nuestra historia pasada, pero es algo que sobre todo sentimos, es sobre todo a nivel emocional (p. 6).

${ }_{63}$ Guidano (1998b), en efecto, concluye lo siguiente: El self narrador es el self que trata de compactar la experiencia, es el que se ve desde afuera y que actúa directamente [...] mientras que el self protagonista, el que está actuando, el que actúa, es el que nos da más que el otro, el sentido de diversidad, de extrañeza, de discrepancia respecto a la continuidad que mantenemos y este es un trabajo continuo, actuar en primera persona sintiéndonos protagonistas y también al contarnos, compactar, reordenar, reorganizar o asimilar la discrepancia que hemos vivido, en la que nos parece ser una continuidad, en la que nos reconocemos dentro de esa continuidad. Entonces, este transformarnos para pasar del self protagonista a pasar a ser self narrador es lo que nos da coherencia, es lo que le da un orden a nuestra historia de vida, y de esta manera con la intervención del self narrador sobre el self protagonista, la historia de vida se convierte en una historia dotada de una univocidad (de casi una necesidad). Es la intervención del self narrador que transforma todo lo que es casual en destino, el que hace que se transforme en destino. Nada queda afuera de esto, nada permanece afuera (p. 7). 
Para Guidano, la conciencia del sí mismo es un proceso sistémico que emerge en la relación entre experimentar y explicar, entre el proceso dialéctico tácito del self system de traducir lo excepcional a lo canónico. Por esto, Guidano afirma que: «la comprensión es inseparable de la experiencia humana y en consecuencia, existir significa literalmente conocer ${ }^{64}$. El yo, entonces, un proceso autoorganizado en continua articulación a lo largo de la vida y que adquiere, con el tiempo, un sentido unitario en su desarrollo ortogenético ${ }^{65}$. La función tácita del self es esencial para la sobrevivencia; uno no podría hacerlo si para comprender se viese obligado a explicarse narrativamente todo lo que es y todo lo que le acontece.

El sameness y el selfhood constituyen la experiencia privada y tácita del self, lo que Guidano denominó «Yo», pertenecientes a la esfera pre-verbal. La narración del yo es llamada por el autor «Mí». Existe, por tanto, un «Mí» que simboliza la actuación del «Yo». En este continuo proceso de traducir la experiencia en conocimiento personal se esgrimen simbolizaciones con diversos grados de complejidad, las últimas de las cuales son, precisamente, las explicaciones.

Para el autor, el surgimiento del lenguaje en los humanos —específicamente del lenguaje temático-, posibilitará el ordenamiento de los acontecimientos en forma de episodios narrados secuencializadamente ${ }^{66}$. Esto entrega continuidad temporal a la experiencia emotiva y constituirá lo que Guidano llama: «estructura narrativa de la experiencia humana ${ }^{67}$. Así, el lenguaje estructurará la experiencia emocional permitiendo la articulación de la experiencia en una "trama narrativa» con características temporales ${ }^{68}$. Por esto, para Guidano, la identidad personal en su aspecto explícito es una «identidad narrativa». Según el autor, tal fenómeno solo se puede desprender de la capacidad del self system de experimentarse a sí-mismo como sujeto (The experiencing "I»; "Yo») y como objeto (The appraising; «Mí») ${ }^{69}$.

La reorganización de la experiencia en una trama narrativa es un proceso abierto que se desarrolla durante toda la vida, e intenta buscar constantemente una verdad narrativa que permita mantener un sentido de continuidad y coherencia entre el protagonista de la propia historia personal (Yo) y el narrador (Mí) ${ }^{70}$.

Podemos observar que Guidano pone énfasis en la comprensión de los procesos tácitos individuales que posibilitan la narrativa del self. Esto no significa en absoluto que lo explícito esté de más o que no añada nada nuevo a la comprensión del fenómeno. El self tiene, para Guidano, un componente constitutivo radical que es tácito, pero que tiene un complemento que es explícito y que corresponde a las narraciones.

${ }^{64}$ Guidano (1994, p.18).

${ }_{65}$ Cfr. Balbi (1994); Ferrer y Skoknic (1998); Guidano (1994). Sobre esto, Guidano (1987) sostiene que: "[La identidad] puede describirse como un sistema de conocimiento cuyo desarrollo a través de la vida está regulado por el principio de progresión ortogenética; esto significa que el sistema procede hacia niveles más integrados y complejos de orden estructural» (p.10).

${ }_{66}$ Guidano (2001a).

67 Guidano (2001a); Arciero y Guidano (2000).

${ }_{68}$ Podemos evidenciar una clara relación entre esta idea y el pensamiento de MerLEau-Ponty, M. (1984), quien afirma lo siguiente: «Todas nuestras experiencias, en cuanto que son nuestras, se disponen según un antes y un después, porque la temporalidad, en lenguaje kantiano, es la forma del sentido íntimo, y el carácter más general de los hechos psíquicos» (p. 418).

${ }_{69}$ Guidano (1994) indica: «La interdependencia entre experiencia y explicación que subyace en la autocomprensión tiene el correlato de un proceso incesante de circularidad entre experiencia inmediata de uno mismo (el "yo" que actúa y experimenta) y el sentido de sí-mismo que emerge como resultado de autorreferirse de forma abstracta a la experiencia en curso ("Mí") [...] El sí mismo como sujeto ("Yo") y como objeto ("Mí") aparecen por lo tanto como dimensiones irreductibles de una dinámica de la mismidad cuya direccionalidad depende del devenir de nuestra experiencial vital» (p. 20).

${ }^{70}$ Guidano (1994; 2001a). 
Lo individual y privado está representando en las dos sensibilidades anteriormente descritas, las que constituyen el «Yo» que actúa» y el «Mí», en su parte tácita, que simboliza la experiencia y en su parte explícita que la narra.

La inserción de lo social en el fenómeno de la identidad personal se manifiesta en la apertura que tiene el selfhood a nuevos significados para la experiencia privada que intenta integrar. El selfhood por consiguiente tiene un aspecto privado y uno social. En su aspecto social, el selfhood es capaz de integrar significados provenientes de narraciones externas.

El self para Guidano encuentra su comprobación en lo social, dado que el self system emplea experiencias simbolizadas por otras personas para dilucidar aspectos confusos de la propia experiencia. Es decir, cada uno se siente a sí, sin embargo, este "yo» se despliega a través de un estilo que dice directa relación con el modo como cada cual se experimenta a sí mismo en las relaciones interpersonales. Este estilo es, además, un modo de relacionarse con uno mismo y es modulado según el estilo afectivo temprano que cada cual haya tenido de niño con sus figuras parentales ${ }^{71}$ (patterns de apego). Tal interacción temprana se inicia con la sincronía fisiológica entre bebé y cuidador ${ }^{72}$, y fija las regularidades emotivas recurrentes para el niño, lo que, retroalimentado en la relación, constituye el dominio emotivo originario de las narraciones. De este modo, la relación vincular activa predominante configura ciertos dominios emotivos que tienden a hacerse recurrentes y estructuran una manera prototípica (canónica/sameness) de, además, sentirse con el mundo y con los otros ${ }^{73}$. Esto constituye el origen socio-interaccional del sentido de continuidad y coherencia del self system ${ }^{74}$.

La inserción de lo social en lo privado es permitida, entonces, por la apertura del selfhood, que pone la experiencia personal a la luz de las experiencias semejantes de otros por medio de símbolos compartidos, entre los que está el lenguaje.

Las narraciones, efectivamente, pueden aportar información acerca de los procesos tácitos del self, y lo hacen efectivamente porque representan las experiencias de otras personas que podrían, eventualmente, aportar comprensión acerca de la propia experiencia. Las narraciones son pues, significativas, porque recogen información de mí mismo que tiene algún parecido con las experiencias de otros ${ }^{75}$. El «Yo» llega a reco-

${ }_{71}$ Guidano afirma que la búsqueda humana de significado debe considerarse como el desarrollo de una comprensión proactiva influida por la condición intersubjetiva ineludible del ser humano (relaciones cuidadores-bebés, lazos sociales, cohesión de grupo, etc.), que definirá una serie de emociones prototípicas (apego, amor, protección, duelo, etc.), que permiten compartir significados en la dimensión lingüística (Cfr. Guidano, 1994).

72 Bowlby (1988); Besoain y Santelices (2009). Sobre esto, Guidano (1994) señala lo siguiente: «Ya nadie discute que, desde las primeras fases del desarrollo, el niño está dotado de sentimientos básicos, así como de la capacidad básica para comunicarlos [... La propensión a modular las contingencias ambientales con reacciones emotivas expresa muy bien la aptitud del niño para sintonizar con otros, y en particular, con otros seres significativos como sus cuidadores» (p. 32).

${ }_{73}$ Guidano (1994) señala lo siguiente: «La interdependencia y reciprocidad de los ritmos psicofisiológicos entre el niño y su cuidador parece ser intrínsecamente codependientes, y coexistir con la actividad del niño en el ordenamiento de la percepción del sí mismo y del mundo desde el primer momento (p. 33).

${ }^{74}$ Guidano distingue cuatro O.S.P. sobre la base de los cuatro estilos afectivos de apego descritos por Bowlby (1974; 1988). Éstas son: O.S.P. obsesiva (apego ambivalente), O.S.P. depresiva (apego evitante), O.S.P. dápica (apego ambiguo) y, finalmente, O.S.P. fóbica (apego ansioso). Para una mayor revisión, Cfr. GUIDANO (2001a, b). ARCIERo (2005), además distingue dos modos de vincularse con la realidad social: Las dos primeras O.S.P. mencionadas corresponden a un estilo inward, con un locus de control interno, autorreferidos y vigilantes de la propia experiencia corporal como principal gatillante emotivo, y 2) Un estilo outward, al cual pertenecen las últimas dos O.S.P., con un locus de control externo y, predominantemente, vigilantes de la evaluación externa. Para una mayor revisión (Cfr. ARcIERo, 2005).

${ }_{75}$ Según varios autores, el fenómeno de «contraste-comprobación» intersubjetivo de la experiencia personal se inicia desde el nacimiento de los bebés en su relación de apego con sus cuidadores, lo que 
nocerse como un sí mismo a través de la «imagen reflejada» proporcionada por los otros, lo que es permitido por la dimensión intersubjetiva de la experiencia humana ${ }^{76}$.

Finalmente, podemos observar que, para Guidano, el self ocurre en dos niveles simultáneos: el nivel de la experiencia inmediata (tácito), y el nivel simbólico, una de cuya funciones explícitas es el lenguaje narrativo. Luego, existen dos modalidades de reorganizar la experiencia tácita: los símbolos pre-verbales y los verbales o narraciones explícitas.

\section{RESUMEN DEL PROBLEMA Y ANÁLISIS CRÍTICO}

Al comparar las ideas de Guidano y Gergen se advierte una discusión teórica y epistemológica fundamental que subyace en sus comprensiones del self. Para Guidano existe una organización tácita que es sentida emotivamente en cada persona y a partir de la cual se estructuran las narraciones que la hacen comprensible explícitamente ${ }^{77}$. En cambio, para Gergen no existe un self real, sino el efecto del entrecruzamiento de narraciones ajenas ${ }^{78}$. Acá, la disputa es una discusión en torno al origen del self y al origen y la naturaleza de la realidad y de las narraciones que sustentan la conciencia de sí mismo. En síntesis, la cuestión en la discusión es entender si el self es un fenómeno experimen$\operatorname{tado}^{79} \mathrm{o}$ una construcción conversacional ${ }^{80}$. A continuación presentamos algunas críticas a los argumentos que sustentan al modelo de Gergen:

4.1. Aunque el aporte de autores como Gergen, ha sido importante para poner de relieve el valioso aporte de la red de significados sociales en la comprensión del self $f^{81}$, es necesario señalar que también ha operado en éste una suerte de injustificada reducción en la comprensión del self y la realidad.

Gergen tiende a reducir las narraciones del self a meros estilos conversacionales definidos contextualmente. Su supuesto es que toda narración describe aspectos observables de una conversación. Sin embargo, el aspecto conversacional —argumenta Guida-

comienza a desarrollar sus capacidades mentalistas básicas para la atribución de intenciones al cuidador. Se fijan ciertas regularidades emotivas en la retroalimentación bebé-cuidador, por lo que el niño comienza a experimentar un estado más o menos recurrente de sentirse en la relación para con el otro y para consigo mismo. Esta situación encuentra su fundamento biológico, entre otros, en las redes neuronales compuestas por las «neuronas espejo». Para profundizar el fundamento biológico de la propuesta: Cfr. BowLBY (1988) y Milán (2007); Rizzolatti y Sinaglia (2007); Naranjo (2008).

${ }^{76}$ Guidano (1994) señala que: «La aptitud acrecentada para la sintonía sincrónica con las intenciones ajenas mediante interacciones lingüísticas va acompañada por un mayor ordenamiento de los ritmos psicofisiológicos que prestan continuidad a la experiencia inmediata ("Yo"). Junto a esto, la capacidad para verse desde las perspectivas ajenas se ve acrecentada por las aptitudes de abstracción lingüística, lo que un sentido reconocible sobre la percepción de la propio continuidad e igualdad ("Mí"). Esta capacidad, separada de la inmediatez del contexto interaccional, se convierte en un instrumento esencial para reordenar la experiencia inmediata y estabilizar la coherencia interna» (p. 26).

77 Cfr. Guidano (2001a); Arciero y Guidano (2000).

78 Gergen y KeIth (1985); Gergen (1992).

79 Guidano (1998a).

80 Gergen (1992).

${ }_{81}$ Tal es el caso de Linares, J., quien desde la teoría sistémica, indica claramente que el concepto de identidad personal fusiona la experiencia individual con el mundo de lo relacional, en lugar de oponerlos como lo sugiere Gergen. Sobre esto, LinAREs (2006) indica que: «La narrativa constituye algo así como el tejido conectivo de la personalidad. Pero la narrativa en bruto no permite el desarrollo de una estructura. Para ello necesita un principio organizador o jerárquico, el órgano rector, el núcleo duro, el punto de anclaje o como lo queramos llamar: es la identidad» (p. 1). 
no por otro lado- es el punto de llegada en la narración del Yo, no un punto de partida. Dicho en otras palabras, podemos observar que cada uno arriba con una significación de sí mismo a una narración compartida; y, entonces, la conversación se transforma en un evento individual y social a la vez, articulando la significación social y la individual en el juego interaccional. Cada uno arriba a una conversación con una conciencia de sí mismo previa.

Contrastando con Gergen, para explicar algunos aspectos de la narrativa del self, Guidano se detiene en un momento previo al empleo conversacional del lenguaje. Este momento es el siguiente: el de la sensación del Yo susceptible de ser narrada. Guidano señala que, en primer término, el modo de conversar de una persona depende del tipo de coherencia emotiva y de continuidad de vida que ha puesto en su contexto de pertenencia ${ }^{82}$. Si no fuese de este modo, ¿cómo podríamos explicar, por ejemplo, aquellas situaciones donde experimentamos algo en la interacción social, pero no logramos ponerlo en palabras que los demás logren entender? En tales situaciones, las palabras no logran definir la experiencia, pero no por ello la experiencia deja de ser sentida, ni menos la experiencia de ser sí mismo en la conversación deja de existir. Sobre esto, Arciero, comparte la opinión de Ricoeur, al señalar que: «[la conversación] busca llevar al lenguaje una experiencia, un modo de vivir en el mundo, que precede y requiere de ser dicho» ${ }^{83}$.

4.2. En su propuesta, Gergen reduce la historia personal a la biografía personal, es decir, reduce la historia experimentada a la mera historia narrada. Esto tiene como consecuencias dos problemas: a) existen tantas identidades como biografías. Pero con esto no se logra explicar qué vincula una biografía con otra; $b$ ) luego, si el sentido temporal del Yo se manifiesta en sus narraciones, el self se fragmenta. Sin embargo, hay algunos detalles que Gergen no advierte: 1) cada sujeto posee elementos de su vida que nunca han sido incorporados a su autobiografía, permaneciendo tácitos, pero que posteriormente pueden, efectivamente, aflorar ${ }^{84}$; 2) Gergen no toma en cuenta el sentido pre-temporal del self, que es el que permite que una narración temporal sea aceptada como biográfica en tanto se ajusta a este sentido, por ejemplo: que las edades tempranas tienen que ver con el pasado y la vejez con el futuro; que hay sensaciones actuales presentes y hay fantasías en el futuro y recuerdos en el pasado, etc. ${ }^{85}$. Es este sentido pre-temporal del self el que permite organizar y articular la narración misma del Yo, incluso, en la ejecución del un rol, como sugiere Gergen.

4.3. Gergen indica que el self en la actualidad es, entre otras cosas, un self saturado de narraciones externas al sujeto. Coherentemente con su supuesto, Gergen indica que el superávit informacional al que está expuesto el sujeto termina saturándolo, fragmentando y diluyéndolo. Finalmente, el self deja de existir como tal, transformándose en un «empty self». Dicho en términos del autor: "un yo realmente saturado, deja de ser un Yo» ${ }^{86}$. Sin embargo, esta posición se torna problemática en los siguientes puntos:

82 Guidano (1998).

83 Ricoeur en Arciero (2009, p. 8).

84 BRUNer (1986) plantea lo siguiente: «La experiencia vital es más rica que el discurso, las estructuras narrativas organizan la experiencia y le dan sentido, pero siempre hay sentimientos y experiencias vividas que el relato dominante no puede abarcar» (p. 143).

${ }_{85}$ Guidano (1998) indica que: «El hecho de que puedan surgir recuerdos autobiográficos requiere el prerrequisito de la existencia de un sentido [pre-temporal] del self » (p. 6). Lo mismo opina RICOUER (1986; 1993) al referir que el fundamento de la narrativa, es precisamente, pre-verbal.

${ }_{86}$ Gergen (1992, p. 26). 
4.3.1. Tal como Guidano explica, si la identidad y el self se diluyen y dejan de existir (empty self), entonces resulta imposible explicar su desarrollo ${ }^{87}$. Según diversos autores $^{88}$ una explicación como la de Gergen se torna inconcebible al observar el proceso de progresión ortogenética y ontogenética de los organismos humanos, los cuales van accediendo a niveles más integrados y complejos en su orden estructural psíquico y biológi$\mathrm{co}^{89}$. Guidano concluye, en el mismo sentido que los autores anteriores, que lo observable en el desarrollo humano es una integración que aumenta con los años, generando una coherencia interna que regula toda la actividad y la conducta del sujeto ${ }^{90}$. Por tanto, Gergen se queda sin respuesta al intentar explicar la psicología del desarrollo de su propuesta de self.

4.3.2. A pesar del énfasis que Gergen coloca en la historicidad o biografía personal como elemento constitutivo del self, el propio autor sacrifica esta biografía en favor del rol presente que ejecuta el sujeto. Mucho más importante que lo que he narrado acerca de mí mismo, es el rol que ejerzo aquí y ahora. Para Gergen, toma relevancia el estado actual del self, sobre el proceso evolutivo personal que le da consistencia a la manera personal de ser del sujeto. Sobre esto, Guidano señala que el concepto de empty self adscribe una clara tendencia a comprender la identidad personal de manera descontextualizada $^{91}$. El concepto de Gergen se torna cuestionable al no tomar en cuenta los aspectos histórico-evolutivos del self ${ }^{92}$. En consecuencia, en la propuesta de Gergen, lo transeccional se impone a lo autobiográfico como caracterización de la historia personal.

4.3.3. Guidano critica que Gergen y Máscolo, entre otros autores ${ }^{93}$, crean en una progresión ontogenética, a pesar de haber postulado un self fragmentado. En efecto, surgen algunas interrogantes al observar esto: ¿cómo es que algo fragmentado se desarrolla en una creciente integración sin dejar de estar fragmentado?, ¿se puede explicar el desarrollo integrativo de la fragmentación?, ¿no son pues el «desarrollo integrativo» y la «fragmentación» posiciones no complementarias?, que el self se desarrollo de forma cada vez más integrada, ¿no implica esto, exactamente, lo contrario a que se su desarrollo sea fragmentado?

4.3.4. Otra observación en la línea del punto anterior es que autores como Gergen y Máscolo indican que el self deja de existir, aunque reconocen su desarrollo integrativo. Con esto se cae en la siguiente contradicción: que algo que no existe —el self-, se desarrolle. En efecto, si Máscolo y Gergen señalan que la mente y el self mismo no son nada más que fraccionamiento, y a su vez, reconocen que el desarrollo ocurre en una dirección creciente de integración: ¿cómo se explica el desarrollo crecientemente inte-

${ }^{87}$ Una explicación del desarrollo coherente con el supuesto conversacional describiría al self como un «recipiente», que desde su niñez se va llenando de conversaciones que lo definen, hasta que en etapas más avanzadas termina por saturarse por el superávit de información que permiten los actuales avances tecnológicos [Cfr. GERgEN (1992); GuIDANO (1998a)].

88 Guidano (1994) y QuiÑones (1998).

${ }^{89}$ Los orígenes de esta propuesta están representados en autores como: Werner (1957), PRIGOGINE y Stengers (1984) y Prigogine (1996), entre otros.

90 Guidano (2000).

91 GuIDANO (1998).

${ }_{92}$ Guidano (1998a) indica: «Me refiero al concepto de self vacío, the empty self», de Gergen. Gergen tiene un libro muy famoso El Yo Saturado, que es prácticamente el self actual y disuelto. Es una entidad ilusoria y emblemática de la situación post-moderna. Yo creo, que esto es un modo de acercarse al problema de la transformación de la conciencia contemporánea, sacándola del contexto evolutivo y de desarrollo» (p. 1).

93 Gergen (1994) y Máscolo (2002). 
grativo de un self que es nada?, ¿cómo se explica el desarrollo creciente de un self que no existe?, ¿acaso se puede explicar el desarrollo integrativo de la nada?, ¿se puede explicar el desarrollo de la «no existencia»?

Por otra parte, la tesis del empty self se vuelve difusa generando la siguiente pregunta: ¿el self deja de existir o existe, pero fragmentado? Ambas modalidades son recurrentemente enunciadas por Gergen, pero éste no es claro al advertir en que momento un self es fragmentado, o cuando el self fragmentado deja de existir; no indica si hay un criterio "cuantitativo» que define el nivel de superávit del self; tampoco indica si la saturación o la fragmentación pasan por experimentarse de tal manera. Esto, claramente lo alejaría de sus postulados. Por otro lado, Gergen tampoco explica por qué un self saturado deja de ser un self y no es, simplemente eso, «un self saturado».

4.3.5. En referencia a lo antes señalado, Gergen no es claro al referirse a la vaciedad del empty self, ni al explicar en qué momento un self que solamente es saturado se transforma en un empty self. Para el autor, el self deja de existir, es decir, se hace nada. Pero en este punto advertimos que, si el self fuese vacío, no habría conversaciones, fragmentaciones, palabras, ni nada posible de ser narrado; no habría posibilidad de noticia del yo, y en consecuencia, no sabríamos nada de nosotros. Pensemos, por lo demás, en las siguientes dificultades: si el self es nada, ¿es una nada narrable?, ¿esta nada se transforma en algo al ser narrada?, pero si ésta nada es narrada, ¿con esto no deja de ser una nada? En efecto, Gergen no repara en un detalle, a saber: que toda narración es narración de algo. Si el self es empty self, no existe ni soporte experiencial ni social que fundamente la narración del sí mismo.

4.3.6. A pesar de que Gergen omite una y otra vez la experiencia como soporte de la narración, existen algunos momentos en los cuales la experiencia del sujeto pareciera ser importante. Por ejemplo, en ciertas experiencias de vacío. Sin embargo, el autor no las pondera apropiadamente e incluso parece confundir ciertas experiencias de vacío, con un vacío real del self. Esto puede ser refutado, al pensar en los siguientes ejemplos: a) la continuidad del self de las personas que retoman su vida familiar después de haber despertado de un coma profundo o nuestra propia continuidad cuando despertamos cada mañana; $b$ ) la continuidad del self de monjes que meditan y que, según afirman, han anonadado su conciencia en ciertos momentos de trance. En cada uno de estos casos parecen existir, por decirlo de algún modo, experiencias de vacío más que vacíos del self, lo cual se demuestra porque la continuidad es retomada una vez que estos episodios concluyen. Podemos ver, por tanto, que a pesar de vivir experiencias de vacíos en donde el sujeto no posee narraciones contextuales a las cuales anclarse, ello no implica la fragmentación del self de los sujetos que experimentaron tales vacíos. Los sujetos se reincorpran y siguen teniando noticia de su yo a lo largo de su acontecer. Parece ser, entonces, que lo que prima en la continuidad del sí mismo no son las narraciones sociales del self, sino que la sensación tácita del sí mismo, la que podemos poner, en un segundo momento de la existencia humana, en palabras.

4.4. Para el autor la compresión del self se configura exclusivamente en su narración. En efecto, Gergen afirma lo siguiente: «sin las formas del lenguaje no se podría afirmar que se tenga experiencia alguna $»^{94}$. Efectivamente, podemos estar de acuerdo en que sin palabras, la experiencia no se podría «afirmar», «decir», «conversar» o «narrar». Sin embargo, esto no significa en absoluto que esta experiencia — por ejemplo, la experien-

94 Gergen (1992, p. 149). 
cia del sí mismo- no exista. Por lo demás, tampoco podemos excluir que la experiencia del sí mismo pueda ser simbolizada mediante otros medios distintos a las formas habituales del lenguaje verbal, esto es, el arte, la música, los síntomas, etc.

4.5. Gracias a los aportes de la psicología del desarrollo podemos saber que solamente hacia el primer año de vida los bebés comienzan a articular palabras con el fin de referirse a los objetos ${ }^{95}$. Antes de esto la relación con el entorno se enfoca, principalmente, en la sintonía de los ritmos fisiológicos entre el bebé y su cuidador ${ }^{96}$. Si Gergen está en lo cierto, habría que concluir, entonces, que los bebés no poseen experiencia, ni experiencia de ser sí mismos antes de poder articular palabras, antes de poder «narrar». Sin embargo, esto genera algunos problemas difíciles de responder, tales como: ¿los bebes no se sienten a sí mismos?, ¿los bebés no tienen noticia de su acontecer?, ¿cómo se explica el fenómeno del llanto activado por experiencias puramente fisiológicas (no mediadas por palabras)? ${ }^{97}$, ¿acaso se niega la existencia de tal experiencia pre-verbal?, ¿cómo se explican las interrelaciones que se generan entre madres y bebés que están por nacer? ${ }^{98}$.

4.6. El autor no parece valorar la importancia de sentirse siendo quien se es; alguien, por lo demás, distinto a otros. Si bien la narración del self puede variar en diferentes contextos - lo que ineludiblemente ocurre- esto no implica que el self se fragmente. En efecto, la experiencia de ser sí mismo en los diversos contextos es sólo mía y es reconocible tácitamente, emocionalmente y preverbalmente por mí. Es posible, incluso, reconocer diversas narraciones y diversos contextos acerca de uno mismo; pero uno mismo es quien las reconoce y quien las somete a juicio. La experiencia de sentirse a sí mismo como el «quien» en los diversos contextos es continua. Es más, cuando las narrativas son divergentes a lo que experimenta, uno mismo es quien puede sentirse confundido, precisamente, porque uno mismo no deja de sentirse. Sobre esto, Williams James denominó self social a esta capacidad del self de variar su actuación sin perder su continuidad identitaria9.

4.7. Cuando se conversa o se narra algo, uno elige — con más o menos cuidadolas palabras que utiliza. Si las narraciones se escogieran simplemente desde la base de narraciones anteriores - como parece sugerir Gergen-, el problema remitiría al infinito (reducción al infinito). Es decir, no hay, ni son necesarias, previas evaluaciones explícitas de las palabras que vamos a emplear. Esto solo ocurre en contextos muy limitados, por ejemplo, en discursos públicos, discursos formales, etc., pero no en la vida habitual.

95 Gleitman y NeWrort (1995); NewPort y Aslin (2000); Zorzi (2000). Es importante señalar que —según BRUNER (1986) - los bebés comienzan a participar en las conversaciones con sus cuidadores, por medio de la etapa del «balbuceo». El surgimiento de las primeras palabras coincide en la mayoría de los casos con el inicio de la marcha, lo que asegura un nivel de coordinación psicomotor básico que posibilita la interacción verbal (Cfr. GleitMan y NewPort, 1995).

96 Bowlby (1988); Guidano (1994), entre otros.

${ }_{97}$ Una buena introducción a la comprensión de las experiencias activantes del llanto se evidencia en el estudio realizado por Bell y Ainsworth (1972).

${ }_{98}$ Las experiencias en el bebé en etapa de gestación posibilitan la interacción con su madre sin articulación alguna de palabras. GuidANo (1994) señala que hay suficientes datos que indican que existe un "aprendizaje intrauterino» como resultado de la participación activa en la regulación de los ritmos fisiológicos entre madre e hijo. Para revisar los estudios clásicos, Cfr. Iannirubeto y Tajani (1981); Milani ComPARETTI (1981). Para una comprensión actualizada, revisar: FELDMAN (2005).

${ }_{99}$ Cfr. JAMES (1890-1980). 
Guidano postula que el empleo de las palabras obedece a la función de expresar emociones de base (la sensación del sí mismo), las cuales, a su vez, son interpretaciones tácitas de uno mismo y de la realidad. Según Gendlin la narrativa personal es una actividad situada y se ve determinada por elementos implícitos, tales como el estado de ánimo, la experiencia, el interés, la práctica, el cuerpo, los acontecimientos, las situaciones y el lugar que se ocupa en el mundo ${ }^{100}$. Las sensaciones del self precondicionan la elección de los símbolos que buscan definirlo ${ }^{101}$. Estas sensaciones del Yo no pueden ser arbitrarias porque no son voluntarias. Por ejemplo, los términos «Don Felipe» y «Felipito» pueden tener como referencia a la misma persona, sin embargo, la sensación en el individuo determinará la selección de las palabras que se ocuparán en contextos diferentes para referirse a sí mismo de modo pertinente ${ }^{102}$.

4.8. Gergen supone que la noticia que tiene el yo de su acontecer en distintos momentos surge en las conversaciones y en las palabras que la definen. Sin embargo, esto no explica el modo concreto como cada sujeto se apropia de tales narraciones. Se desconoce si uno las elige, las acepta, se siente obligado a tomarlas para sí, es inducido, las introyecta mecánicamente, etc. Lo mismo cabe decir, en realidad, acerca de toda preferencia narrativa o explicativa acerca del self. Gergen no indica el proceso mediante el cual se produce la apropiación significativa de la narración de mi Yo. El autor solo indica que las narrativas son foráneas, pero no especifica como ellas pasan a ser «mías». Al omitir los procesos tácitos que fundamentan una conversación, Gergen no explica el proceso mediante el cual los sujetos eligen ciertos símbolos y argumentos por sobre otros para referirse a sí mismos y los demás ${ }^{103}$.

4.9. Gergen afirma que su propuesta, a diferencia de la de otros autores socioconstruccionistas, no es antirrealista. Es más, considera que esto es un mal entendido. En efecto, el autor afirma lo siguiente:

«[...] Esto no significa que "nada existe" o que "nunca se puede conocer la realidad" - los malentendidos corrientes del construccionismo-, sino que al intentar articular lo que existe, al ubicarlo en el lenguaje, penetramos el mundo de los significados generados socialmente [...] Bajo esta premisa, el construccionismo nos ayuda a recordar el aforismo que tanto amaba Gregory Bateson: "el mapa no es el territorio" ${ }^{104}$.

100 Gendin (1993).

101 Esto se torna evidente en el caso de la sensación. No es lo mismo la palabra «cuerpo» (símbolo) a la «sensación del cuerpo». Se torna cuestionable la propuesta de Gergen, la cual implica concebir el cuerpo como encerrado en una burbuja esperando ser atrapado por las palabras para que entonces se lo pueda sentir. Sin embargo, el cuerpo es y se manifiesta tácitamente y de un modo sensible. No es lo mismo la sensación del cuerpo, que la narración de éste. La primera no solo es diferente a las palabras que lo definen, sino que también es anterior, posibilita su narrativa.

102 Sobre esto, GENDLIN (1993) concluye lo siguiente: «Determinamos que la misma afirmación puede poseer diferentes significados implícitos en el contextos. Al decir esto estamos distinguiendo entre afirmación y contexto, y entre explícito e implícito [...] El lenguaje hace algo más de lo que dice» (p. 4).

103 Gendin (1993) señala: «Tu estado de ánimo sabe lo que has querido decir y por qué, lo que intentas evitar y por qué, tal vez no lo sabes explícitamente, pero tu estado de animo lo sabe» (p. 5). Sobre este asunto, Merleau-Ponty (1984) es claro al indicar lo siguiente: «[...] Tenemos un medio directo para acceder a lo que [el lenguaje/la narración] designa, tenemos la experiencia de nosotros mismos, de esta consciencia que somos; es con esta experiencia que se miden todas las significaciones del lenguaje y es ésta lo que hace justamente que el lenguaje quiera decir algo para nosotros» (p. 15).

104 Gergen (2001, p. 5). 
Sin embargo, si solo podemos conocer mediante la narrativa, no parecen haber argumentos que realmente le permitan a Gergen emplear otros recursos de conocimiento. Dicho de otro modo, desde la posición de Gergen y aunque afirme lo contrario, no se podría distinguir el mapa (las narraciones) del territorio (la realidad).

4.10. Si para Gergen solo podemos obtener conocimiento de nosotros mismos exclusivamente desde la narración explícita, y a su vez, ésta hace referencia a discursos anteriores ¿qué ocurre en el caso de la información que nos entregan nuestras sensaciones corporales acerca de nosotros mismos?, ¿no es acaso esto, una experiencia no mediada por palabras?, ¿qué pasa en los juegos y las expresiones artísticas?, ¿qué ocurre en los rituales y rumiaciones obsesivas?, ¿un síntoma — que no es una acción narrativa explícita- no nos permite conocernos?, ¿cómo se explica la espontánea empatía que se produce entre personas que no han conversado antes?

4.11. Si para Gergen la narrativa genera la experiencia de la realidad, y entre ésta, la de las cosas materiales, ¿qué son estas cosas materiales? La solidez de este papel que Ud. tiene entre sus manos, ¿equivale a las palabras «solidez de este papel que Ud. tiene entre sus manos»?, ¿lo que experimentamos como perturbaciones perceptivas, acaso son en realidad fantasías creadas por las palabras?; si es así, ¿¿estamos solos en el universo?, ¿no podríamos, por este mismo expediente, desaparecer, si nos narramos como inexistentes?, ¿no son las sensaciones, más bien, las que expresan la existencia de un mundo olfativo, uno gustativo o uno visual en un aparato perceptivo humano? ${ }^{105}$. Parece ser que se necesita cierto "grado de realismo" para narrar algo real acerca del self.

Siguiendo las ideas de Gergen, ¿qué pasa con aquellas especies que no han desarrollado un lenguaje como el nuestro?, ¿qué pasa con los animales que no articulan su interacción en base a palabras?, ¿se negará entonces la existencia de mundos perceptivos para tales especies? Esto se vuelve problemático para el autor, dado que, si lo niega, niega gran parte del funcionamiento del reino animal, entre otras cosas; y si no lo niega, reconoce que existe una realidad más allá de las palabras. El argumento de Gergen se vuelve poco convincente, por ejemplo, al ver el grado de interacción animal-animal y animalmedio, los cuales desarrollan su adaptabilidad en base a mundos perceptivos no conversacionales, pero no por ello, inexistentes o faltos de orden.

4.12. Para Gergen, el yo participa en diversos contextos donde recibe narraciones y rotulaciones diferentes. Si comparamos los contextos, según el autor, los discursos se tornan incoherentes e inconexos y, en consecuencia - postula Gergen- el self se observa fragmentadamente. Gergen es claro en este asunto, e indica lo siguiente: «La saturación social nos proporciona una multiplicidad de lenguajes del yo incoherentes y desvinculados entre sí» ${ }^{106}$. Guidano ha argumentado de muchas formas que el self es, en primer lugar, tácita, pero también aporta, esta vez, un argumento que proviene de la dimensión de lo explícito. Lo explícito tiene más de un nivel: lo temático, es decir, el modo como habitualmente narro las cosas — que es el nivel de las tesis de Gergen-, y lo autorreflexivo. Pues bien, el nivel autorreflexivo puede permitir dar cuenta o argumentar en favor de la propia unidad del self. Por ejemplo, cuando uno se pregunta acer-

105 El físico, matemático y filósofo Roger Penrose (2002) afirmó sobre el problema lo siguiente: «Cualquier punto de vista filosófico serio debería contener al menos una buena dosis de realismo» (p. 270), lo que en el caso del conocimiento de la realidad física se torna su condición de posibilidad.

106 Gergen (1992, p. 26). 
ca de quién se es realmente en todos estos contextos diferentes en los que participa. Gergen omite este nivel, lo cual le lleva a cometer —según Guidano- un error metodológi$\mathrm{CO}^{107}$, a saber: asumir como característica de lo observado, la posición supuestamente fragmentada del observador, algo que Arciero califica como un «juego de espejos que disemina al si mismo en imágenes, referencias y reflejos» ${ }^{108}$. Para explicar esto, Guidano acude a las ideas W. James, quien indica que en la observación están implicados dos aspectos: Los aspectos sustantivos y los aspectos transitivos ${ }^{109}$. Los aspectos sustantivos son aquellos que aparecen en la conciencia del observador al momento de observar, por ejemplo: imágenes, colores, flujos de palabras, etc. Los aspectos transitivos —el sentido de continuidad, unicidad personal y unitariedad del self- no se observan cuando se habla de cosas cotidianas sino cuando se reflexiona. Gergen, precisamente por su error metodológico, solo observa los aspectos sustantivos, no los transitivos, y por ello le es inevitable observar una fragmentación.

4.13. Según el supuesto de la interdependencia precaria de Gergen, el locus of meaning —el lugar donde ocurre y se actualiza el significado personal del Yo- está en las redes conversacionales ${ }^{110}$. Junto a Guidano, sin embargo, rechazamos esta tesis. Siguiendo la argumentación de Guidano, podemos distinguir, dos problemas básicos en la argumentación de Gergen:

4.13.1. El autor no explica que el yo sea quien comprenda lo que se narra. Supongamos que, como sugiere Gergen, el yo deja de existir abrumado por las significaciones externas producto de la «saturación social». Pues bien, si realmente yo no soy el que significa lo que narro, tal parece que, entonces, debiera existir alguna entelequia encargada de entender por mí y, en consecuencia, hablo de lo que no entiendo tal como si yo fuera una terminal computacional o un autómata ${ }^{111}$. En efecto, la externalización del significado, implica consecuentemente la inexistencia de comprensión de parte del Yo. Gergen sugiere esta problemática —apoyándose en Baudrillard — de la siguiente manera: «Nuestra esfera privada ha dejado de ser el escenario donde se desenvuelve el drama del sujeto reñido con sus objetos [...]; Ya no coexistimos como dramaturgos ni como actores, sino como terminales de redes de computadoras múltiples ${ }^{112}$.

4.13.2. En segundo lugar, tal parece ser que los demás comparten el mismo problema que yo. Si el locus of meaning es externo y no hay espacio interior para significar nada, ninguno de los que me habla entendería lo que habla, porque todo meaning está en un «entre» ellos y yo, la interacción social se transforma en una sociedad de autómatas.

4.14. Las consecuencias prácticas del pensamiento de Gergen generan algunos problemas éticos. Si yo no significo lo que narro, es decir, no lo entiendo por mis propios términos, como consecuencia, yo no soy responsable de los actos que se siguen de mis deliberaciones. En otras palabras, si hay un self que tiene un locus of meaning comple-

107 Guidano (2001) comenta que: «Al no tener en cuenta la distinción entre observador y observado, es muy fácil, muy natural, que uno tome por hecho que el self es nada más que la fragmentación que aparece ante la conciencia de quien observa» (p. 382).

108 Arciero (2005, p. 12).

109 Cfr. JAMES (1890-1980).

110 Guidano (1998).

111 BaLBI (2004).

112 Baudrillard en GERgEN (1992, p. 94). 
tamente externalizado, el Yo no puede responsabilizarse de nada ${ }^{113}$. Los castigos y premios los debiera recibir «la trama conversacional» quien es la que significa el self. Acá, incluso el recurso a la «co-responsabilidad» tampoco resuelve el problema, porque para que haya uno "co»-responsabilidad se requieren dos entes, uno de los cuales —el selfGergen declara vacío y con un meaning externo. Se pueden inferir las consecuencias sobre asuntos análogos al de la responsabilidad tales como: la voluntad, la libertad personal y el libre albedrío. En efecto, la idea misma del locus externalizado se opone a tales capacidades, ya que las reduce a la reproducción autómata de significaciones y voluntades foráneas.

4.15. Si el locus of meaning es externo, ¿cómo significa el sujeto el rol entregado por la sociedad; rol que supuestamente posibilita al self según Gergen? Gergen no explica la capacidad que cada uno posee de enjuiciar y demostrar conformidad o disconformidad con los roles ejecutados. En algunos casos, hasta es posible rechazarlos. Si Gergen omite explicar esto, parece ser que el autor transforma al sujeto en una mera reproducción irreflexiva de lo impuesto «desde afuera». Tal como lo señala Balbi, un planteamiento de esta clase, involucra una mente sin subjetividad, un mecanismo similar a un sujeto autómata determinado completamente desde lo social ${ }^{114}$. Finalmente, la posición de Gergen se torna aún más discutible cuando la comparamos con las palabras de Wittgenstein, autor que es citado como apoyo por el propio Gergen. El autor omite la experiencia de significar un rol, pero como Wittgenstein argumenta, cuando un discurso contrasta con la experiencia, tal discurso se vuelve inviable ${ }^{115}$.

4.16. Si bien Gergen ${ }^{116}$ intenta trascender mediante su propuesta socioconstruccionista algunas visiones epistemológicas clásicas del self y de la ciencia en general, tales como el «dualismo sujeto-objeto» o la discusión entre lo «endógeno y lo exógeno», creemos que sus argumentaciones no cumplen su cometido. En efecto, creemos que el autor cae en la denominada "tentación objetivista» cuando intenta explicar la totalidad de los fenómenos de la realidad, del self, el yo y la narrativa por la determinación de las redes conversacional sobre el sujeto ${ }^{117}$.

Si al autor intentaba trascender la visión «adentro-afuera» de los paradigmas clásicos en la comprensión del self, claramente su propuesta radicaliza una de las posiciones, la de «afuera». Tal como hemos observado, para Gergen toda significación personal, todo sustento del self y la realidad se sitúa en la «trama conversacional», en el «afuera»; es más, el autor niega algunos componentes «internos» tales como la sensación privada de sí mismo, entre otros. La comprensión del self de Gergen se transforma en un modelo

113 Guidano (1998a) señala que: «Si imaginamos el significado como descentralizado, hay un locus of meaning que es externo, lo que conduce a una red conversacional y lo que tenemos es siempre una externalización de los problemas. Es decir, todos los problemas son externalizados y son vistos como pertenecientes al sistema social y cultural antes que al individuo» (p. 3).

114 BALBI (2004).

115 Wittgenstein (1953).

116 El autor señala lo siguiente: «Si el construccionismo va a trascender la antinomia exogénica-endogénica y el interminable conflicto que ha generado hasta ahora, entonces debe también abandonar la explicación empirista del conocimiento científico. Al abandonar la dicotomía sujeto-objeto como centro del debate disciplinario, debe también desafiar el dualismo como base de una teoría del conocimiento científico» (GERGEN, 1985, pp. 17-18).

117 GonZÁlEz-Rey (1999) define este término como una forma de explicación del self en base solamente a la relación biunívoca determinista con los elementos presentes de la vida social del sujeto. 
«de afuera hacia dentro» y presenta una visión unidireccional, mecánica, poco integradora, reduccionista y determinista de las relaciones sujeto-sujeto y sujeto-cultura ${ }^{118}$.

Sobre esto, consideramos que el self es claramente influido por la sociedad, pero no consideramos que tal influencia sea en forma de un determinismo lineal. Esta relación no va desde lo social a lo personal, sino que constituye una integración simultánea entre la subjetividad y sociedad. A su vez, el self, si bien siempre integra lo social y al otro ${ }^{119}$, se define ontológicamente en diferencia a los elementos sociales. En efecto, el self es un elemento constituyente de la intersubjetividad, y a la vez y se nutre de ella; tanto self como el ambiente (trama conversacional para Gergen) emergen y se despliegan como dos sistemas en relación sistémica irreductible, existiendo una «interdependencia recíproca indispensable entre ambos ${ }^{120}$.

4.17. La idea de un locus of meaning externalizado se torna problemática cuando analizamos su aplicabilidad al caso práctico de la resiliencia ${ }^{121}$. Si para Gergen, las narraciones contextuales son las que me definen y determinan al self, en el caso de la resiliencia, ¿cómo se hace posible que me pueda sobreponer exactamente a aquello que me define?, ¿al ser resiliente se desarticula el self?, ¿acaso el contexto me narra como resiliente?, ¿no va eso, precisamente, en contra del concepto de resiliencia?, ¿no es la resiliencia justamente un proceso que permite sobreponerme a la vulnerabilidad social, psicológica o económica que mi medio determina? Se torna inevitable hacer tales preguntas cuando observamos el caso de sujetos resilientes que no tienen ninguna definición contextual que implique el sobreponerse a su contexto, y a pesar de todo, lo logran.

4.18. Según Gergen, las actuales condiciones «hipertecnologizadas» ${ }^{122}$ han saturado al sujeto hasta desvanecerlo ${ }^{123}$. Sin embargo, ¿qué sucede con aquellos sujetos que se articulan en contextos ínfimamente tecnologizados, esto es, poco saturados?, ¿qué

118 Sobre esto, GonZÁLez REy (1999) señala que: «Excluir la subjetividad conduce a ignorar la propia historia de lo social en su expresión diferenciada actual, que se expresa en los individuos: La negación del individuo como singularidad, significa ignorar la complejidad de la subjetividad, la cual se constituye de forma simultánea en una multiplicidad de niveles, que pueden ser contradictorios entre sí, pero de cuyo funcionamiento dependen los diferentes momentos del desarrollo subjetivo» (p. 41.)

119 Esta idea es presentada claramente por GuIDANo (1998), quien señala que: «Entonces por esto, el punto que cabe subrayar es que el self y su estructura inherente [...] es dialéctico, en el sentido de que el self siempre incluye al otro. En los primates, los primeros surgimientos de la capacidad de individuación van siempre acompañados, son simultáneos a una percepción, a una apreciación de la capacidad del otro. No es sólo que el self comprenda siempre un sentido del otro, comprende en general un sentido no sólo de los otros, sino de aquello que no es uno del mundo. [...] El hecho de desarrollar un sentido de mí mismo implica también simultáneamente, que yo me siento de un cierto modo respecto al mundo al que pertenezco, y me siento de cierto modo respecto [...] a la normatividad del mundo al que pertenezco» (p. 2).

${ }_{120}$ BALBI (2004, p. 334).

121 Definiremos «resiliencia» como aquella capacidad de los humanos que, a pesar de nacer y vivir en situaciones de alto riesgo y vulnerabilidad, logran desarrollar competencias psicológicas adaptativas viables para sobreponerse a su contexto (KotLIARENCO, CÁcERES y FonTECILla, 1997).

122 GERGEN (1992) señala que: «Con el incremento de las nuevas tecnologías aparece una infiltración en la conciencia cotidiana, de la duda sobre sí mismo, una sutil sensación de insuficiencia que agobia las actividades que se emprenden con una incómoda sensación de vacuidad inminente. Esa sensación de insuficiencia es un producto colateral de la colonización del yo» (p. 113).

${ }_{123}$ Haciendo referencia explícita a avances como la radiofonía, la televisión, el ferrocarril, entre otros, Gergen ha acuñado el término "tecnologías de la saturación social» para indicar que son tales avances y otros más, los que actualmente han permitido la saturación de información del self. Según el autor, esto conduce irremediablemente a su disolución (empty self). Para una explicación del término: Cfr. GERGEN (1992), capítulo 3: «La saturación social y la colonización del Yo». 
ocurre, por ejemplo, con la identidad de un habitante de la caleta Ahui en Chiloé, Chile?, ¿qué ocurre con los habitantes de caleta Tortel, región de Aysén, Chile? ${ }^{124}$. La tesis de la disolución del self no resiste estos ejemplos. La existencia de un tipo de self insaturado sugiere, en consecuencia, la posibilidad de la existencia del self en la actualidad. Con esto, las ideas de Gergen pierden aplicabilidad bajo ciertos contextos.

\section{CONCLUSiOnes}

Las preguntas por el origen de las narrativas del Yo y el origen y la naturaleza de la realidad están lejos de ser un problema resuelto, pero, como ha podido observarse, constituye uno de los problemas fundamentales de la filosofía y la psicología en general y de la epistemología psicológica en particular actualmente. En vista del análisis realizado podemos concluir que:

5.1. No parece convincente el argumento que indica que no existe experiencia de ser sí mismo sin palabras que la refieran, o que no exista realidad más allá del lenguaje. Tal posición, no logra dar cuenta del hecho fundamental de que los humanos sean capaces de cuestionar, criticar y censurar la realidad conversacional y las narraciones sobre nosotros mismos sobre la base de nuestras propias experiencias tácitas del mundo y de nosotros mismos.

5.2. Los argumentos de Gergen se muestran poco convincentes cuando se revisa su aplicabilidad y se las contrasta con los fenómenos cotidianos, tales como la resiliencia, la responsabilidad personal, la significación personal de los roles ejercidos, la voluntad personal, entre otros aspectos.

5.3. Gergen reduce de modo poco convincente la historia personal experimentada a la biografía personal narrada. Con ello, omite dos importantes asuntos: a) explicar los procesos tácitos que fundamentan la narración y simbolización la experiencia de ser sí mismo, y b) ofrecer una comprensión del amplio mundo de fenómenos pre-verbales que también cumplen una función simbólica, tales como el arte, la música, las rumiaciones y ritos obsesivos, entre otros.

5.4. Considero que la distinción que Guidano realiza entre «Yo» y «Mí» en su self system parece explicar de mejor manera los procesos del self que la distinción entre "Yo» y «los otros» realizada por Gergen. En efecto, la distinción de Guidano, no así la de Gergen, permite integrar los procesos tácitos, explícito-narrativos, personales y relacionales a la comprensión del self, logrando describir, articular e integrar tanto los componentes sociales como los individuales de éste.

5.5. Cuando Gergen niega la anterioridad de la experiencia personal respecto de las palabras, omite el análisis del sustento tácito de las relaciones humanas. En efecto, con

${ }^{124}$ Ambos ejemplos son zonas extremas de la geografía de Chile, Latinoamérica. En Ahui no hay señal de teléfono de red fija, tampoco internet. En Caleta Tortel sólo hay un teléfono para 507 habitantes y tampoco hay internet. En ambos casos, el acceso físico se realiza cada cierto tiempo, dado que no hay recorridos de transporte que lleguen regularmente a tales zonas. 
esto niega los componentes que sustentan las conversaciones. Por tanto, niega, entonces, aquello que parece evidente en la vida cotidiana, a saber, la conciencia experiencial del sí mismo y las sensaciones que condicionan muchas veces nuestras narrativas acerca de nosotros mismos.

5.6. Gergen no describe ningún proceso de apropiación de las narraciones. El autor solo indica que el self se constituye en base a narrativas foráneas sin describir con esto ninguna forma de significación de éstas. Junto a Guidano y a Balbi observamos que esta propuesta desemboca inevitablemente en un excesivo ambientalismo y en la objetivización irreflexiva de las narrativas foráneas que definen al sí mismo.

5.7. Si el yo tiene noticia de su acontecer en diversos momentos solo en base a fragmentos, y su continuidad toma curso en los diversos contextos que la definen - observándose, entonces, un self fragmentado-, la propuesta de Gergen no logra dar cuenta de lo siguiente: Que cada uno de nosotros experimenta la continuidad de nuestro sí mismo aunque los contextos cambien. Cada uno se experimenta continuamente como un «quien», sin que el cambio de nuestros contextos implique la escisión o fragmentación nosotros mismos. La experiencia de fragmentación puede estar más cerca del desarrollo de una psicopatología que de la experiencia cotidiana del vivir humano.

5.8. Gergen no pondera la importancia de la influencia de los procesos históricoevolutivos en la narrativa del self. En efecto, sus explicaciones en torno al desarrollo del self parecen inconsistentes, pues, por lo demás, se omite integrar los aportes de la psicología del desarrollo, la neonatología o algunos aportes de la biología, entre otros.

5.9. No podemos negar la «experiencia de saturación», pero cuestionamos la aplicabilidad de la tesis del «self saturado» de Gergen, especialmente, porque podemos observar la existencia de selves que no han sido saturados por entornos tecnologizados, aún, en contextos altamente tecnologizados.

5.10. El concepto de «saturación social del self» propone una clara y muy útil advertencia acerca del modo como algunas personas podrían actualmente experimentar de forma ambigua su relación consigo mismas y con los demás. Pero no podríamos indicar que la saturación del self sea el rasgo distintivo del self en la posmodernidad. Consideramos, entonces, que el concepto implicaría una forma de experimentarse en el mundo. Y si observamos que tanto sujeto y sociedad están en una relación irreductible, tal experiencia del sí mismo, inevitablemente es muestra de las condiciones históricas en las cuales participa éste.

5.11. La tesis del «self fragmentado» no es convincente porque no considera el Yo unitario y tácito que integra la diversidad de narraciones contextuales permitiendo la continuidad del sí mismo. En efecto, Gergen omite considerar el «quien» que narra y articula la multiplicidad contextual.

5.12. La tesis del «empty self» muestra algunas inconsistencias. Si el self es nada, no hay nada en él que se puede ni fragmentar, ni desarrollar. No hay nada que pueda ser narrado. De la nada, nada viene. Si el yo es vacío, no hay nada en él, y, por tanto, él no puede ser causa de sí ni de nada. 
5.13. La idea de que el sujeto construye su identificación y significación personal exclusivamente en base a las narrativas foráneas (locus of meaning externo) se torna discutible cuando observamos sus consecuencias éticas y prácticas sobre temas como la voluntad y la responsabilidad personal. Considerar que el significado del self proviene absolutamente desde el exterior, provoca observar a un sujeto pasivo, autómata y falto de cualquier capacidad reflexiva sobre su proceder.

5.14. Gergen no parece ponderar suficientemente que la alteridad es un momento integrante del self. Simplemente contrapone el concepto de sí mismo y el de alteridad, enfatizando el influjo del otro en el self. No parece considerar suficientemente que el self incluye un momento de alteridad para autorreconocerse como un «quien». Esto lleva a Gergen a negar la experiencia del sí mismo y al self mismo. En contraste con esto, considero que la propuesta de Guidano se torna más explicativa y abarcante del concepto de self. Para Guidano, en el significado personal siempre está contenido el otro, como lo que uno no es.

5.15. Guidano logra incluir en su comprensión de la identidad personal tanto la alteridad como la unicidad personal a través del self system, y más específicamente, por medio de dos sensibilidades: el sameness y selfhood. Éstas, a su vez, permiten la integración de lo individual, lo social, la alteridad y la unicidad en la comprensión de la identidad personal.

5.16. Quisiera indicar que, cada self, en la multiplicidad de roles que ejecuta, posee una manera de ser, que es lo que caracteriza su identidad. Es este "quien» en la diversidad de contextos el que no es tomado en cuenta por Gergen. Es más, inclusive desde el plano de los significados sociales, es más pausible pensar que el self —el «quien de cada cual»— no consiste en llamarme meramente "profesor», "padre», «hombre», o los infinitos roles a los cuales puedo acceder dentro de un espectro cultural determinado, sino que, y es más, es mi experiencia de mí mismo, la que deviene en tanto existencia en el mundo y la que sostiene las posibles identificaciones narrativas.

5.17. Asimismo, la idea de concebir al self como una construcción conversacional, se torna dudosa por una condición gnoseológica y epistemológica fundamental, a saber, que es la misma existencia del self en el mundo la que determina un ordenamiento especial de éste. Toda posibilidad narrativa de la realidad y del sí mismo surge de la existencia previa del sujeto en el mundo, siendo esto, fundamento y soporte de las narraciones. Por tanto, y parafraseando a Merleau-Ponty, nosotros no somos meros «seres vivientes» o "mamíferos, ni siquiera "hombres» o una "conciencia» o cualquiera de los roles que nos entrega la sociedad ${ }^{125}$. Si bien, la zoología, la anatomía, la biología, la psicología social o la política, entre otras dimensiones, nos puedan entregar muchas características, cada uno de nosotros, esto es, nuestra existencia misma, es la fuente absoluta de tales caracterizaciones. Nuestra existencia no procede de nuestros antecedentes, es ésta la que va hacia ellos y los sostiene. Nuestro self no consiste en ser "padre», «hijo» o "profesor», sino que, y es más, consiste en ser aquel que le da consistencia y coherencia a todas mis actuaciones culturales.

125 Cfr. Merleau-Ponty (1984). 
5.18. En síntesis, y habiendo analizado los argumentos de ambos autores, concluyo que la narración explícita del self, constituye uno de los aspectos más distintivos del ser humano, pero de ninguna manera constituye la comprensión completa del fenómeno.

\section{REFERENCIAS}

Arciero, G. (2005): Estudios y diálogos sobre la identidad personal, Buenos Aires: Amorrortu.

- (2009): Mueren los -ismos, vuelve la persona. Entrevista a Giampiero Arciero. Recuperado el 8 de noviembre de 2008 desde http://www.ipra.it/images/Audio/Entrevista\%20GArciero.pdf.

Arciero, G. - Bondolfi, G. (2009): Selfhood, Identity and Personality Styles, Torino: Wiley \& Sons.

Arciero, G. - Guidano, V. F. (2000): «Experience, explanation and the quest for coherence», en R. A. Niemeyer - J. D. Raskin (eds.), Constructions of disorder, Washington, D.C.: American Psychological Association.

BALBI, J. (2004): La mente narrativa, Buenos Aires: Paidós.

BeLl, S. - Ainsworth, M. (1972): «Infant crying and maternal responsiveness», en Child development, 43, 1171-1190.

Besoain, C. - Santelices, P. (2009): «Transmisión intergeneracional del apego y función reflexiva materna: una revisión», en Terapia psicológica, 27(1), 113-118.

Berger, P. - Luckman, T. (1983): La construcción social de la realidad, Buenos Aires: Amorrortu.

Bowlby, J. (1974): La separación afectiva, Barcelona: Paidós.

- (1988): Una base segura, Buenos Aires: Paidós.

Bravo, C. (2002): Hacia una comprensión del construccionismo social de Kenneth Gergen. Seminario de Psicología Social, Santiago de Chile: Universidad Bolivariana.

BRUNER, J. S. (1984): Acción, pensamiento y lenguaje, Madrid: Alianza.

- (1986): «Juego, pensamiento y lenguaje», en Perspectivas, 78, 4-10.

CABRERA, M. (2006): «Lenguaje, experiencia e identidad: La contribución de Joan Scott a la renovación de la teoría de los estudios históricos», en C. Borderías (coord.), Joan Scott y las políticas de la historia, España: Icaria.

Campbell, D. (1974): «Evolutionaty epistemology», en P. SchilpP (comp.), The philosophy of Karl Popper, La Salle: Library of Livings Philosophers.

CRESPO, E. (2001): La constitución social de la subjetividad, Madrid: Catarata.

Collier, G. - Minton, H. L. - Reynolds, G. (2000): Escenarios y tendencias de la psicología social, Madrid: Tecnos.

Deleuze, G. (1989): El pliegue, Barcelona: Paidós.

DERRIDA, J. (1984): «Deconstruction and the Other», en R. KeARney (ed.), Dialogues with Contemporary Continental Thinkers: The Phenomenological Heritage, Manchester: Manchester University Press.

Echeverría, R. (1994): Ontología del lenguaje, Santiago: Dolmen Ediciones.

Eagleton, T. (1998): Las ilusiones de la posmodernidad, Buenos Aires: Paidós.

FERRER, M. - SKonic, P. (1998): La identidad personal como un metanivel autorregulatorio del nivel autorregulatorio emocional: Un modelo evitativo de la progresión ortogenética, Universidad Central de Santiago de Chile. Inédito.

Feldman, R. (2005): «Valoración del desarrollo cognitivo en relación con el crecimiento intrauterine y la interacción madre-hijo durante los primeros dos años», en Pediatrics, 59(2), 130-140.

García-Lorente, J. (2008): «Giro lingüístico y posmodernidad», en Pensamiento: Revista de investigación e información filosófica, 64(241), 473-486.

GENDLIN, E. T. (1993): «Words can say how they work», en R. CREASE (ed.), Heidegger conference proccedings, Nueva York: State University of Nueva York. 
- (2007): Focusing, New York: Bantam Books.

Gergen, K. (1992): El Yo saturado, Barcelona: Paidós.

- (1996): Realidades y relaciones. Aproximaciones a la construcción social, Barcelona: Paidós.

- (2000): "The Self in the Age on Information», en The Washington Quarterly, 23(1), 201-214.

- (1985): «Social pragmatics and the origins of psychological discourse», en K. J. Gergen - K. E. Davis (eds.), The social construction of the person (pp. 111-127), New York: Springer Verlag.

Gergen, K. - KeIth, D. (1985): The Social construction of the person, New York: Springer Verlag.

Gergen, K. - Warhus, L. (2001): «Therapy as social construction: Dimensions, deliberations and departures», en K. Gergen (ed.), Social Construction in Context, Londres: Sage.

Gleitman, L. - NewPort, E. (1995): «The invention of language by children: Environmental and biological influences on the acquisition of language», en L. Gleitman - M. Liberman (eds.), An invitation to cognitive science: Language (pp. 1-24), Cambridge, MA: MIT Press.

GonZÁlez-ReY, R. (1999): La investigación cualitativa en psicología. Rumbos y desafíos, México: International Thompson editores.

Grondin, J. (1996): "La hermenéutica en "Ser y Tiempo"», en Seminarios de filosofía, 9, 75-91.

Guidano, V. F. (1987): The Complexity of Self, Nueva York: Guilford Press.

- (1990): Terapia cognitiva procesal sistémica. Conferencia dictada en la Sociedad de Terapia Cognitiva, Santiago: Inteco.

- (1993): «La terapia cognitiva desde una perspectiva evolutivo constructivista», en Revista de Psicoterapia, 14(15), 89-112.

- (1994): El sí mismo en proceso, Barcelona: Paidós.

- (1995a): «A constructivist outline of human knowing processes», en M. MaHoney (ed.), Cognitive and Constructive Psychotherapies, New York: Springer.

- (1995b): «La autoobservación en la psicoterapia constructivista», en R. NEIMEYeR - M. MAHoney (comps.), Constructivismo en psicoterapia, Barcelona: Paidós.

- (1997): «Estado de la cuestión en la terapia cognitiva posracionalista», en I. CARo (comp.), Manual de Psicoterapia Cognitiva, Barcelona, Paidós.

- (1998a): Psicoterapia: Aspectos metodológicos, problemas clínicos y preguntas abiertas. Congreso Internacional de Constructivismo en Psicoterapia. Recuperado el 2 de marzo de 2008 de: http://www.inteco.cl/temporal/conferencia_guidano.html.

- (1998b): Los procesos del self: continuidad vs. discontinuidad. Recuperado el 30 de marzo de 2009 desde http://www.inteco.cl/articulos/008/texto_esp.htm.

- (2001a): «Vittorio Guidano en Chile», en S. Aronsohn (ed.): Vittorio Guidano en Chile: Compilación de Conferencias, Santiago de Chile: Universidad Academia de Humanismo Cristiano. Recuperado el 20 de febrero de 2008 desde http://www.posracionalismo.cl/imagenes/vguida no.pdf.

- (2001b): El modelo cognitivo posracionalista. Hacia una reconceptualización teórica y clínica, Bilbao: Desclée de Brouwer.

Guidano, V. - Liotti, G. (1979): Elementi di Psicoterapia Comportamentale, Roma: Bulzoni.

Henry, M. (1991): Fenomenología de la Vida, España: Columna.

Hermans, H. J. M. (1993): The Dialogical Self: Meaning as Movement, San Diego: Academic Press.

Hollinger, R. (1994): Postmodernism and the social sciences. A thematic approach, Thousand Oaks: Sage.

IANNIRUberto, A. - TAJANI, E. (1981): «Ultrasonographic study of fetal movements», en Seminars in perinatology, 5, 81-175.

Jubés, B. - Laso, E. - Ponce A. (1890-1980): The Principles of Psychology, Cambridge: Harvard University Press.

- (2000): «Constructivismo y construccionismo: Dos extremos de la cuerda floja», en Boletín de psicología, 69, 71-89.

Kunn, T. (1978): Segundos pensamientos sobre paradigmas, Madrid: Ed. Tecnos. 
Lambruschi, F. (2009): «Cuentos, vínculos de apego y organizaciones de significado personal», en Psicoperspectivas, VIII (1), 112-158.

LiNARES, J. (2006): «Diálogos sobre personalidad, identidad y narrativa», en Redes, 2(16), 83-95.

LydDon, W. (1995): «Formas y facetas del constructivismo en psicología», en R. NIEMEYER - M. MAHONEY (eds.): Constructivismo en psicoterapia, Barcelona: Paidós.

Lyotard, J. F. (1989): La Fenomenología, Barcelona: Paidós.

Mahoney, M. J. (1991): Human change processes, New York: Basic Books.

Máscolo, M. (1994): «Toward a social constructivista psychology: The case of self-evaluate emotional development», en Journal of Constructivist Psychology, 7(2), 87-106.

- (2002): «The Dynamic Construction of Culture, Self and Social Relations», en Psychology \& developing societies, 14(1), 55-89.

Maturana, H. (1988): «Ontología del conversar», en Terapia psicológica, 7(10), 15-23.

- (1989): «Lenguaje y realidad: El origen de lo humano», en J. Luzoro (comp.): Desde la Biología a la Psicología, Santiago: Universitaria.

Maturana, H. - Varela, F. (1984): El árbol del conocimiento, Santiago: Universitaria.

MeAd, G. H. (1934): Mind, self, and society: from the standpoint of a social behaviorist, Chicago: U. of Chicago Press.

Merleau-Ponty, M. (1984): Fenomenología de la percepción, Barcelona: Planeta.

Milani Comparetti, A. (1981): «The Neurophysiologic and Clinical Implications of Studies on Fetal Motor Behavior», en Seminars in Perinatology, 5, 183-189.

Mrtchell, S. (1993): Hope and Dread in Psychoanalysis, New York: Basic Books.

Moscovici, S. (1961): El psicoanálisis, su imagen y su público, Buenos Aires: Huemul.

NARANJo, C. (2008): La regulación emocional. Aportes al trabajo terapéutico desde la neurobiología y la terapia cognitiva posracionalista. Recuperando el 12 de septiembre de 2009 desde http://www. posracionalismo.cl/articulo10.htm.

NARDI, B. (2006): «Rol de los procesos filogenéticos y ontogenéticos en el desarrollo de las organizaciones de significado personal», en Psicoperspectivas, 5(1), 49-64.

Nardi, B. - Bellantuono, C. (2008): «A new adaptive and evolutionary conceptualization of the Personal Meaning Organization (P.M.O.) framework», en European Psychotherapy, 8(1), 5-16.

Neimeyer, R. - Mahoney, R. (1998): Constructivismo en psicoterapia, Barcelona: Paidós.

Nietzsche, F. (1994): Así hablo Zaratustra, Madrid: Alianza.

Newport, E. L. - Astin, R. N. (2000): «Innately constrained learning: Blending old and new approaches to language acquisition», en S. C. Howell - S. A. Fish - T. KeIth-Lucas (eds.), Proceedings of the 24 $4^{\text {th }}$ Annual Boston University Conference on Language Development (pp. 1-21), Somerville, MA: Cascadilla Press.

Owens, C. (1986): «El discurso de los otros: Las feministas y el posmodernismo», en H. Foster (ed.), La posmodernidad, Barcelona: Kairós.

Penrose, R. (2002): La mente nueva del emperador, México: Fondo de Cultura Económica.

PotTer, J. (1996): La representación de la realidad. Discurso, retórica y construcción social, Barcelona: Paidós.

Potter, J. - Wetherell, M. (1987): Discourse and social psychology: beyond attitudes and behavior, London: Sage.

Prigonine, I. (1996): El fin de las certidumbres, Santiago de Chile: Editorial Andrés Bello.

QuiNones, A. T. (1998): «Significado social y viabilidad emocional y narrativa», en F. FrankLIN - C. Nabuco (eds.), Psicoterapia y constructivismo: Consideraciones teóricas y prácticas (pp. 251-270), Brasil: Editora Artes Médicas.

Rattcliffe, M. (2008): The feeling of being, Oxford: Oxford University Press.

RevilLa, J. C. (2003): «Los anclajes de la identidad», en Athenea digital, 4, 54-67.

Ricoeur, P. (1986): Tiempo y narración I, Madrid: Cristiandad.

- (1993): El sí mismo como otro, Madrid: Siglo XX. 
Rizzolatti, G. - Sinaglia, C. (2007): Las neuronas espejo, España: Paidós.

SAMPSON, E. E. (1983): «Deconstructing psychology's subject», en Journal of Mind and Behavior, 4, 135-164.

SARUP, M. (1993): An introductory guide to post-structuralism and postmodernism, Georgia: University of Georgia Press.

SHotTer, J. (1993): Conversational realities, London: Sage.

Stolorow, R. - Aтwood, G. (1992): Contexts of Being: The Intersubjective Foundations of Psychological Life, Hillsdale: The Analytic Press.

Teicholz, J. G. (1999): Kohut, Loewald \& the Postmoderns: A Comparative Study of Self and Relationship, New York: The Analytic Press, Hillsdale.

Vatтıмo, G. (1990a): «Éloge de la pensée faible», en Magazine littéraire, 279, pp. 20-24.

- (1990b): Las aventuras de la diferencia. Pensar después de Nietzsche y Heidegger, Barcelona: Península.

- (1990c): En torno a la posmodernidad, Barcelona: Anhtropos.

- (2004): El fin de la modernidad, España: Gedisa.

WeImeR, W. (1977): «A conceptual framework for cognitive psychology: Motor theories of the mind», en R. Shaw - J. Bransford (eds.), Perceiving, acting, and working, Hilldale: Erlbaum.

WERNER, H. (1957): «The concept of development form a comparative and organismic point of view», en D. B. HARRIs (ed.), The concept of development (pp. 125-148), Minneapolis: University of Minnesota Press.

Wetherell, M. - Potter, J. (1996): «El análisis del discurso y la identificación de los repertorios interpretativos», en A. Gorgo - J. LinazA (eds.): Psicologías, discursos y poder, Madrid: Visor.

Wittgenstein, L. (1953): Philosophical Investigations, Blackwell: Oxford.

- (1988): Tratatus Lógico-Philosophicus, Buenos Aires: Alianza.

PhD ( $)$ in Philosophy, Departament of Philosophy

PABLo LÓPEZ-SiLVA

The University of Manchester, United Kingdom

pablo.lopez.silva@gmail.com

[Artículo aprobado para publicación en diciembre de 2012] 